\title{
III. Das Nationalkomitee „Freies Deutschland“ im Widerstreit der Konzeptionen
}

Der Zeitpunkt zur Gründung des Nationalkomitees „Freies Deutschland“ wurde in Abhängigkeit zur Auflösung der Komintern und der anschließenden Überführung ihres Apparates in „wissenschaftliche Forschungsinstitute" festgelegt. Aber das am 12./13. Juli feierlich unterzeichnete Manifest war nur ein halber Erfolg, weil sich kaum höhere Offiziere und vor allem keine Generäle angeschlossen hatten. Die sowjetischen Politoffiziere standen somit unter dem Druck, den Erfolg des Nationalkomitees durch die nachträgliche Einbeziehung der Offiziere abzusichern. Das gelang schließlich zwei Monate später mit der Gründung des Bundes Deutscher Offiziere (BDO), der sich am 11./12. September 1943 konstituierte und sich sofort dem NKFD anschloß. Allerdings hatte die Einbeziehung von Offizieren, deren politischen Vorstellungen viel Raum gelassen wurde, nachhaltige Konsequenzen für die Zielsetzung des Nationalkomitees. Die Folge waren Abstimmungsschwierigkeiten zwischen UPVI, GlavPURKKA und ZK der VKP (b).

\section{Exilregierung}

Die Gründung des Nationalkomitees im Juli 1943 wurde von den Stabsoffizieren und Generälen boykottiert. Obwohl bei den zumeist in Stalingrad gefangengenommenen Offizieren Zweifel an Hitlers Kriegführung - weniger am NS-Regime insgesamt - vorhanden waren, wollten sie nicht mit Antifa-Schülern und Deserteuren zusammenarbeiten. Das Zusammengehen mit Mannschaftsdienstgraden, die „unsoldatisches" Verhalten an den Tag legten, war ihnen nicht recht. Die Offiziere dachten eher an eine Interessenvertretung kriegsgefangener Offiziere als an ein "Anti-Hitler-Komitee“. Die Propagandisten von 7. Verwaltung und UPVI stellten sich darauf ein und setzten ihre Werbungen in moderater Form fort. Das führte zum Erfolg. Viele der bei den Vorverhandlungen zum Nationalkomitee abgesprungenen Stabsoffiziere gehörten bald darauf der Initiativgruppe zur Schaffung eines Offiziersbundes an ${ }^{1}$. Noch im Juli 1943 formulierte die Initiativgruppe einen Appell an die kriegsgefangenen Offiziere, in dem sie die „Zusammenfassung aller guten Kräfte zum Neubau unseres Reiches“ forderten². In Absprache mit dem Chef des Glav-

1 Steidle, Das Nationalkomitee „Freies Deutschland“, S. 26; ders., Entscheidung an der Wolga, S. $321 \mathrm{ff}$.; Bredt, Die Entstehung des Bundes Deutscher Offiziere, S. $86 \mathrm{ff}$.

2 „Eine Weiterführung des Krieges bis zur völligen militärischen Niederlage führt unvermeidlich zu einer Besetzung und wahrscheinlich auch Zerstückelung Deutschlands, was es abzuwenden gilt. Dies ist ein Gebot der Liebe zu Volk und Heimat. (...) Weite vaterlandsliebende Kreise des deutschen Volkes an der Front und in der Heimat sehen dieses Schicksal drohend herannahen und warten auf eine Befreiung von dieser Regierung und Zusammenfassung 
PURKKA, Ščerbakov, galt dieser Aufruf bei der weiteren Werbung für den Offiziersbund als inhaltliche Grundlage ${ }^{3}$. Die Gruppe, der bis zu diesem Zeitpunkt noch keine Generäle angehörten, siedelte am 16. August in das Lager des NKFD nach Lunevo um. Dorthin wurden die Generäle Otto Korfes, Martin Lattmann und Walther von Seydlitz, später noch Edler von Daniels, gebracht, um sie zur Mitarbeit in dem zu gründenden Offiziersbund zu bewegen ${ }^{4}$. Sowjetischerseits waren die Erwartungen hoch gesteckt. Stalin, so schrieb Dimitrov in seinem Tagebuch, soll anläßlich der Gründung des Nationalkomitees gesagt haben: „Der Kampf um die Rettung Deutschlands vor dem Untergang, für die Wiederherstellung der demokratischen Rechte und Freiheiten des deutschen Volkes, für die Errichtung einer parlamentarischen Ordnung usw. - das müßten die Aufgaben des antifaschistischen Komitees der deutschen Patrioten sein. "5 Und Ščerbakov erläuterte in einem Dekret des GlavPURKKA vom Juli 1943, daß sich das NKFD die Aufgabe stelle, eine deutsche Regierung zu bilden 6 .

Die direkten Verhandlungen mit den Generälen wurden vom Chef der operativen Abteilung des UPVI, General Mel'nikov, geführt. Mel'nikov - so die Memoiren der Generäle - trat in diesen Verhandlungen als Vertreter der sowjetischen Regierung auf. So erinnert sich Korfes: „General Melnikow gab die Beurteilung der Kriegslage, wie sie die sowjetische Staatsführung habe, bekannt und legte die Absichten und Grundsätze der Politik dar, die die Sowjetregierung einem Deutschen Reich gewähren wolle, das sich von den Nazis befreit haben würde."7 Auch Daniels bestätigt, daß Mel'nikov „die Ansicht der höchsten Stellen der Sowjetunion" vertreten habe ${ }^{8}$. Seydlitz bezeichnet in seinen Memoiren Mel'nikovs Ausführungen als „Erklärung der Sowjetregierung“. In der entscheidenden Sitzung mit den noch schwankenden Generälen habe der UPVI-General die Zusicherung gegeben: „Gelänge es dem BDO, die Wehrmachtsführung zu einer Aktion gegen Hitler zu bewegen, die den Krieg beende, noch bevor er auf deutschem Boden durchgefochten würde, so wolle

aller guten Kräfte zum Neubau unseres Reiches. Wir Offiziere sind verpflichtet, uns für diese hohen vaterländischen Ziele mit aller Hingabe einzusetzen. Uns muß die Pflicht unserem Volke gegenüber höher stehen, als alles andere.“, „An die deutschen Offizierslager in der UdSSR" vom 24. 7. 1943, RGASPI 495/77/22, Bl. 112+RS; vgl. Reschin, General zwischen den Fronten, S. 43 ff.

3 Manuil'skij an Ščerbakov am 4. 8. 1943, RGASPI 495/77/22, Bl. 109; vgl. Reschin, General zwischen den Fronten, S. $15 \mathrm{ff}$.

4 Scheurig, Verräter oder Patrioten, S. $54 \mathrm{ff}$.

5 Dimitroff, Tagebücher, Eintrag vom 12.6. 1943.

6 Auszugsweise Wiedergabe der Direktive bei Bernikov, Die propagandistische Tätigkeit des NKFD und des BDO, S. 113; siehe auch Vsevolodov, Dic propagandistische Tätigkeit des NKFD und BDO, S. 121.

7 BArch Abt.Potsdam $90 \mathrm{KO}$ 10/183, Bl. 22-23. Die hier zitierten „Erinnerungen“ sind eine Reaktion von Korfes auf eine Anfrage Bodo Scheurigs vom 22. 11. 1960. Im Dezember 1960 trafen sich die in der DDR lebenden Korfes, Lattmann, van Hooven und von Frankenberg, um zu beraten, ob sie und wie sie auf die Fragen Scheurigs antworten sollen. Bei den hier zitierten Gedanken handelt es sich um ein aus der Diskussion heraus entstandenes Thesenpapier, das vermutlich die Grundlage eines Antwortschreibens hätte bilden sollen. Ob der Brief abgeschickt wurde, geht aus der Akte nicht hervor.

8 Daniels - Niederschrift über die Ausführungen des Generals Melnikow in der Nacht vom 2. zum 3. 10. 43, S. 97. Die Datierung auf den Oktober 1943 kann nicht stimmen, die Besprechung muß in der Nacht vom 22. auf den 23. 8. 1943 stattgefunden haben; siehe folgende Anmerkung; siehe auch Gerlach, Die Werbung der Generale, ebenda, S. 94 ff. 
sich die Sowjetunion für ein ,Reich in den Grenzen von 1937‘ einsetzen. Die österreichische Frage wurde meiner [Seydlitz'] Erinnerung nach dabei nicht erwähnt. (...) Selbstverständlich werde die Sowjetunion dabei auch für das Bestehenbleiben einer deutschen Wehrmacht eintreten. Bedingung sei lediglich eine bürgerlichdemokratische Regierung, die durch Freundschaftsverträge mit dem Osten verbunden sein sollte."9 Mel'nikovs Zusicherungen hatten nicht die Autorisation der sowjetischen Regierung, auch wenn die Generäle in diesem Glauben gelassen wurden. Vermutlich machte er die Zusicherungen in Erwartung einer schnellen Bereitschaft der Generäle zur Zusammenarbeit. Er sah sich dabei möglicherweise sogar gedeckt durch das Dekret Ščerbakovs zur Gründung des NKFD, in dem dieser von der Übernahme von Regierungsverantwortung durch das Nationalkomitee gesprochen hatte.

Mel'nikovs Verhalten stieß indes auf den Protest des Rates für militärpolitische Propaganda, der die politische Verantwortung für die Propaganda zu tragen hatte. Manuil'skij, der an den Gesprächen nicht direkt beteiligt war, erhob sofort Einspruch, denn Mel'nikov hatte zusammen mit den Generälen eine Erklärung verfaßt. Im Namen von Ščerbakov setzte er einen Brief an Stalin auf: „Die Frage eines Friedensschlusses, die zentrale Aussage des Dokumentes, ist von den Autoren nicht richtig gestellt worden. Da das Dokument auf dem Territorium der UdSSR verfaßt wurde, wird es im Ausland zweifelsohne als Ausdruck des Standpunktes der sowjetischen Regierung betrachtet werden. Folglich kann die Veröffentlichung des Dokumentes in den verbündeten Ländern als Anlaß zu feindlichen Angriffen auf die UdSSR dienen. Ebenso könnte die in dem Dokument beharrlich vorgebrachte Behauptung, der Erhalt der Stärke der deutschen Armee und der Kampf gegen ihre Zersetzung seien unerläßlich, gemeinsam mit dem Appell zur Festigung der Freundschaft mit der UdSSR vom Ausland als eine etwaige Tendenz unsererseits ausgelegt werden, in Europa einen Block zweier Armeen zu gründen: den Block der deutschen und der Roten Armee." 10 Auch auf zentraler Ebene des NKVD wurde die Problematik einer „Regierungserklärung“ an kriegsgefangene deutsche Generäle erkannt. Um den entstanden Schaden zu begrenzen, vermerkte der stellvertretende NKVD-Chef Kruglov auf dem Bericht des UPVI an Berija: „Die Dokumente sind inhaltlich noch nicht befriedigend. Es wird weiter an ihrer Verbesserung und ihrer Endfassung gearbeitet." 11

Die weiteren Verhandlungen mit den Generälen führte nicht Mel'nikov, sondern Manuil'skij. Unter Vermittlung von NKFD-Präsident Weinert gelang es ihm, die Gründung des BDO einerseits nicht zu gefährden und andererseits die Verabschiedung einer für die Sowjetunion außenpolitisch vertretbaren Erklärung zu erreichen. Am 27. August konnte Manuil'skij den Erfolg an Ščerbakov melden. In dem neu formulierten Aufruf an die Generäle und Offiziere der Wehrmacht hieß es nun: „Das nationalsozialistische Regime wird niemals bereit sein, den Weg, der allein zum Frieden führen kann, freizugeben. Diese Erkenntnis gebietet Ihnen, dem

9 Seydlitz, Stalingrad, S. 286; vgl. Bericht Mel'nikovs an Berija vom 23. 8. 1943, in: Rešin, Sojuz nemeckich oficerov, S. 87; ders., General zwischen den Fronten, S. $28 \mathrm{f}$.

10 Von Manuil'skij ausgearbeitete Vorlage für Ščerbakov für einen Brief an Stalin vom 26.8. 1943, RGASPI 495/77/37, Bl. 2; vgl. Reschin, General zwischen den Fronten, S. 32 f.

11 Reschin, General zwischen den Fronten, S. 33 f.; ebenda, S. 31, ist der Brief an Berija im Faksimile wiedergegeben. 
verderblichen Regime den Kampf anzusagen und für die Schaffung einer vom Vertrauen des Volkes getragenen Regierung einzutreten. Nur eine solche Regierung kann die Bedingungen für einen ehrenvollen Ausweg unseres Vaterlandes aus dem Kriege herbeiführen und einen Frieden sichern, der nicht das Elend Deutschlands und den Keim neuer Kriege in sich trägt. Verweigern Sie sich nicht Ihrer geschichtlichen Berufung. Nehmen Sie die Initiative in Ihre Hand, und Wehrmacht und Volk werden Sie unterstützen." 12 Dieser Passus ging wörtlich in den Gründungsaufruf des Bundes Deutscher Offiziere ein, der am 11./12. September 1943 von 95 Offizieren unterschrieben wurde ${ }^{13}$.

Noch auf der Gründungsfeier des BDO erklärte der zum Präsidenten gewählte General von Seydlitz den Anschluß des Offiziersbundes an das Nationalkomitee. Auf der dritten Vollsitzung des NKFD am 17. September wurde der Zusammenschluß offiziell bestätigt. Zwar behielt der BDO immer seine eigenen organisatorischen Strukturen - Präsidium, Vorstand, Delegationen -, aber faktisch ging er im Nationalkomitee auf. Einsiedels Kritik, daß der BDO mit seinem Beitritt zum NKFD „bereits seine Aufgabe erfüllt und seine weitere Existenz jeden Sinn verloren hat" 14 , trifft dennoch nicht zu. Zwar überschätzte Seydlitz seinen Einfluß, aber aufgrund der anfangs gemachten Zusicherungen Mel'nikovs konnte er mit Recht annehmen, daß die Vorstellungen des BDO seitens der sowjetischen Regierung höchste Aufmerksamkeit erhalten würden ${ }^{15}$. Gleich nach der Gründung des BDO begannen die Generäle und Offiziere über die Formen des Kampfes gegen Hitler nachzudenken. Bereits am 17. September unterbreitete Seydlitz Mel'nikov den Plan, aus den Resten der in Stalingrad in Kriegsgefangenschaft gegangenen 6. Armee ein dreißigtausend Mann starkes Korps aufzustellen, mit dem eine neue deutsche Regierung sich nach dem erfolgreichen Sturz Hitlers absichern könne. An NKVDChef Berija berichtete das UPVI: „Nach Meinung von Seydlitz' soll dieses Korps nach dem Sturz Hitlers die Stütze einer neuen deutschen Regierung sein. Die neue Regierung kann seiner Meinung nach vom deutschen Nationalkomitee und vom ,Bund Deutscher Offiziere' gebildet werden." 16

In den folgenden Wochen entstand mit Wissen des NKVD ein detaillierter Plan über ein Luftlandeunternehmen zur Absetzung der deutschen Regierung in Berlin. Der BDO schlug vor, sich in persönlichen Briefen an die kommandierenden Generäle der Wehrmacht an der Ostfront zu wenden und sie zum Bruch mit Hitler aufzufordern. Außerdem müsse der Kontakt zu namhaften Persönlichkeiten in Deutschland hergestellt werden. Der zweite Teil des BDO-Papiers beschäftigte sich mit militärischen Planungen, ausgehend von der Frage, „ob es nicht möglich ist,

12 „An die deutschen Generale und Offiziere, an Volk und Wehrmacht“, MMNA 1463/22. Eine russische Übersetzung schickte Manuil'skij als Anlage seines Briefes vom 27. 8. 1943 an Sčerbakov, RGASPI 17/128/40, Bl. 29-32.

13 „Aufruf an die deutschen Generale und Offiziere! An Volk und Wehrmacht!“, FD Nr. 8,9/1943 vom 15.9. 1943, S. 1; ediert in: Sie kämpften für Deutschland S. 157 ff.; Scheurig, Verräter oder Patrioten, S. 189 ff.; zur Entstehungsgeschichte siehe auch Lewerenz, Zum Entstehen des Bundes Deutscher Offiziere, S. $167 \mathrm{ff}$.

14 Einsiedel, Tagebuch der Versuchung, S. 100.

15 Seydlitz, Stalingrad, S. $291 \mathrm{f}$.

16 Mel'nikov und Petrov an Berija am 17. 9. 1943; zitiert nach: Reschin, General v. Seydlitz, der BDO und die Frage einer deutschen Befreiungsarmee, S. 228; ders., Psevdonim - „svoboda“, S. 138. 
eine zahlenmäßig kleine und kampfkräftige Armee aus den Kriegsgefangenen zu bilden, die bei der Machtergreifung von der neuen Regierung in Deutschland eingesetzt werden könnte." Berija und sein Stellvertreter Kruglov wurden am 25. September über Seydlitz' Pläne informiert' ${ }^{17}$. Zur unmittelbaren Reaktion des NKVD liegen keine Dokumente vor.

Nach dem Bekanntwerden der Ergebnisse der Moskauer Außenministerkonferenz vom Oktober 1943, auf der sich die Alliierten auf das gemeinsame Kriegsziel der bedingungslosen Kapitulation Deutschlands einigten („unconditional surrender“), fragte Seydlitz bei Mel'nikov an, „ob die Grundlagen, auf die sich die Ziele und Aufgaben des Bundes Deutscher Offiziere stützen und die die Basis meines Beitritts und meiner Mitarbeit im Bund Deutscher Offiziere sind, nach wie vor gelten und in der Arbeit und Propaganda des Bundes der Offiziere beibehalten werden können"18. Seydlitz’ Beunruhigung über die Moskauer Konferenz war verständlich, denn nur solange die Sowjetunion bereit war, mit dem Deutschen Reich bzw. einer deutschen Exilregierung in Verhandlungen zu treten, konnte der BDO Erfolg haben. Vor dem Hintergrund der sich anbahnenden alliierten Einigung über die militärische Niederwerfung und Besetzung des Deutschen Reiches kam es dann auch im Laufe des Novembers 1943 zu Spannungen zwischen den Offizieren und den Kommunisten im Nationalkomitee. Der BDO wollte an seinem bisherigen Konzept des geordneten Rückzuges der Wehrmacht, der durch Verhandlungen mit den Kommandierenden an der Ostfront erreicht werden sollte, festhalten. Gegenüber Mel'nikov hatte Seydlitz erklärt, daß dadurch einer Besetzung durch sowjetische Truppen - die zweite Front war im Herbst 1943 noch nicht eröffnet - zuvorgekommen und einer neuen Reichsregierung ohne Hitler staatliche Souveränität zugestanden werden könne ${ }^{19}$. Die KPD dagegen befürwortete eine „ZersetzungsPropaganda", die sich um den Erhalt der Wehrmacht nicht zu kümmern brauche, sondern lediglich auf eine militärische Schwächung und infolgedessen auf eine politische Destabilisierung des Deutschen Reiches hinarbeiten müsse. Diese Auseinandersetzungen waren weniger der Kampf zwischen dem „rechten“ - nationalkonservativen - und dem „linken“ - kommunistischen - Flügel des NKFD ${ }^{20}$, als vielmehr der Ausdruck der nebeneinander herlaufenden Konzeptionen von BDO und KPD, die sich beide der sowjetischen Unterstützung gewiß glaubten. Denn während der $\mathrm{BDO}$ weiterhin die Unterstützung des NKVD zu genießen meinte, begann die KPD im Herbst 1943 in Absprache mit Dimitrov die Grundzüge ihrer Deutschlandplanung festzulegen ${ }^{21}$.

17 Von Seydlitz ausgearbeiteter „Bericht über die Pläne zur Formierung deutscher Kampfverbände aus Kriegsgefangenen" als Anlage des Schreibens Mel'nikovs an Berija und Kruglov vom 25. 9. 1943, in: Rešin, Psevdonim - „svoboda“, S. 140 ff.; siehe auch Seydlitz’ Planungen in: Reschin, General zwischen den Fronten, S. 112 ff. In der Anlage befindet sich eine Aufstellung über die im Großraum Berlin befindlichen Flughäfen und eine detaillierte Berechnung der benötigten Flüge, um 45000 Mann nach Deutschland zu fliegen; vgl. ders., Seydlitz, der BDO und die Frage einer deutschen Befreiungsarmee, S. $230 \mathrm{f}$.

18 Seydlitz an Mel'nikov am 8. 11. 1943, zitiert nach Reschin, General zwischen den Fronten, S. $128 \mathrm{f}$.

19 Ebenda.

20 Scheurig, Verräter oder Patrioten, S. $116 \mathrm{ff}$.

21 Vgl. „Nach Hitler kommen wir“, S. 71 ff.; zur Deutschlandplanung der Exil-KPD siehe auch Morré, Kommunistische Emigranten, S. $279 \mathrm{ff}$. 
Die Diskussionen im Nationalkomitee wurden von der operativen Abteilung des UPVI aufmerksam verfolgt, allerdings ohne daß sie eingegriffen hätte ${ }^{22}$. Propagandistisch stützten sich UPVI und GlavPURKKA voll und ganz auf die Autorität und das Einflußvermögen der Generäle des BDO, das durch eine offene Parteinahme für die Kommunisten im NKFD offenbar nicht untergraben werden sollte. Seydlitz fuhr in Begleitung von Mel'nikov bzw. Petrov insgesamt zweimal (im Oktober 1943 und im Februar 1944) persönlich an die Front und suchte das Gespräch mit den Kommandierenden der Wehrmacht ${ }^{23}$. Derart hofiert begann der BDO, die Propaganda des NKFD im Sinne des Offiziersbundes auszulegen, was den Protest Ulbrichts hervorrief ${ }^{24}$. Als die Generäle des BDO Ulbricht gar unter Hinweis auf Absprachen mit Mel'nikov übergingen, beklagte dieser sich darüber bei Manuil'skij: „Es ist aber völlig unzulässig, daß den deutschen Generälen gestattet wird, verschiedene Instanzen gegeneinander auszuspielen. Ich bitte um eine klare Mitteilung, ob es wahr ist, daß den deutschen Generälen zugesichert wurde, daß bei Abfassung von Briefen an deutsche Generäle ein Offizier der RA [Rote Armee] die militärische Lage erklärt. Wenn so etwas vereinbart wird, muß uns das mitgeteilt werden, da ich nicht die Absicht habe, mich weiterhin in eine solche unhaltbare Lage bringen zu lassen." 25 Im Mittelpunkt des sowjetischen Interesses standen im Frühjahr 1944 nicht die Kommunisten, sondern die Generäle des BDO.

Anfang Februar 1944 unterbreitete Seydlitz ein weiteres Mal den Plan eines deutschen Korps: Um das Nationalkomitee in Zukunft auf eine reale Macht stützen zu können, solle in Analogie zur „Deutschen Legion“ von 1812 eine „deutsche Befreiungsarmee" gegründet werden ${ }^{26}$. Das Korps solle an der Front gegen die loyal zu Hitler stehende Wehrmacht kämpfen. Darüber hinaus diene es „zur Unterstützung aller gegen Hitler kämpfenden Kräfte für den Fall der sich auflösenden Wehrmacht und der Gefahr des Ausbruchs eines Bürgerkrieges". Das Korps gewährleiste den notwendigen Spielraum „zum aktiven Handeln für die Bildung einer demokratischen Regierung" und trage nach dem Sturz Hitlers „zur Abwehr von gegen eine demokratische Regierung gerichteten Bewegungen" bei27. Die Vorstellungen des $\mathrm{BDO}$ hatten sich somit zwar von unmittelbaren Putschplänen entfernt, er betrachtete aber das Nationalkomitee - genauer gesagt den BDO - als eine Art deutsche Übergangsregierung, die die Regierungsmacht in Deutschland mit militärischer Ge-

22 Vgl. UPVI-Arbeitsbericht vom 30. 11. 43, in: Rešin, Sojuz nemeckich oficerov, S. 97.

${ }^{23}$ Reschin, General zwischen den Fronten, S. 79 ff. und S. 154; Seydlitz, Stalingrad, S. $310 \mathrm{f}$. und S. $335 \mathrm{ff}$.

24 „In Bezug auf die Taktik des NK [Nationalkomitee] zog er [Seydlitz] die Schlußfolgerung, daß die Losung: ,Stellt die Kampfhandlungen ein und geht auf die Seite des NK über', nur für eingekesselte Truppen gelte“, Ulbricht an Manuil'skij am 19.2. 1944, RGASPI 495/77/38, Bl. 54.

25 Ulbricht an Manuil'skij am 8. 3. 1944, RGASPI 495/77/38, Bl. 6.

26 Es ist erstaunlich, wie häufig insbesondere die Generäle die Parallele zu den historischen Ereignissen der Jahre 1812/13 suchten. Das Verhalten des preußischen Generals Yorck und die von ihm unterzeichnete Konvention von Tauroggen - im NKFD-Manifest als historisches Vorbild zitiert - übten eine starke Faszination aus, vgl. Diesener, Geschichtspropaganda; ders., Militärpolitische Propaganda, S. $335 \mathrm{ff}$.; ders., Historisches in der Zeitung „Freies Deutschland“, S. 772 ff.; Morré, Das Nationalkomitee Freies Deutschland und der Mythos von Tauroggen.

27 Zitiert nach Reschin, Seydlitz, der BDO und die Frage einer deutschen Befreiungsarmee unter Stalin, S. 236; russische Edition: ders., Psevdonim - „svoboda“, S. $146 \mathrm{ff}$. 
walt erkämpfen und anschließend sichern müsse. Möglicherweise hatte Seydlitz dabei nicht nur das historische Vorbild, sondern auch die nationalen Kampfverbände vor Augen, die auf sowjetischem Boden aus polnischen, tschechischen und rumänischen Kriegsgefangenen gegründet worden waren ${ }^{28}$.

Die drei führenden Generäle des BDO - Korfes, Lattman und Seydlitz - betrachteten sich alle auf ihre Art als Führungspersönlichkeiten im Kampf gegen Hitler. Jeder der drei schrieb eine Denkschrift, wobei die von Seydlitz verfaßte im weiteren die größte Beachtung erfuhr. Als erster legte Korfes im Sinne einer Rechtfertigung vor der Nachwelt die Motive zur Gründung des BDO dar. Ausgehend von einer ausführlichen Analyse der militärischen und politischen Lage erklärte er, warum die Spitzen der Wehrmacht unter Brechung ihres Eides Hitler stürzen müßten: „Der Umsturz erhält die Wehrmacht und den für jeden Staat gerade in ernster Außenlage wichtigsten Machtfaktor. Der Entschluß der Wehrmacht verschafft dem politischen Entschluß, den Krieg zu beenden, freie Hand. Der Waffenstillstand, die Zurückführung des Heeres in die Heimat und die Demobilisierung erfolgen nach Regel und Ordnung. Der deutschen Heimat wird der Kampf feindlicher Heere auf deutschem Boden und der aus einem Zusammenbruch entspringende Bürgerkrieg erspart."29 Vor dem Hintergrund der Korfes-Denkschrift bekommt der Plan einer deutschen Befreiungsarmee eine andere Konnotation: Die Wehrmacht als einzige wirksame Kraft gegen Hitler ist zugleich die Chance für die Zukunft Deutschlands, sofern sie den territorialen und gesellschaftlichen Zusammenhalt Deutschlands bewerkstelligen kann. Die projektierte Befreiungsarmee sollte ein Sammelbecken aller für die Rettung des Deutschen Reiches Kämpfenden bilden, sozusagen den Kern einer neuen Wehrmacht, auf die sich die neue Regierung - hervorgegangen aus dem NKFD - stützen würde.

Den Gedanken einer zukünftigen deutschen Regierung auf der Basis des NKFD baute Seydlitz in seinem Memorandum aus, das Mel'nikov am 26. Februar erhielt ${ }^{30}$. Im Gegensatz zu Korfes bezog er, mit Blick auf die Zusicherungen Mel'nikovs vom August 1943, die aktive sowjetische Unterstützung in seine Pläne ein: „Die Regierung der UdSSR hat die Bildung und die Tätigkeit des Nationalkomitees ,Freies Deutschland' und des Bundes Deutscher Offiziere gefördert und in vielfacher Beziehung unterstützt. Die gemeinsamen Interessen im Kampf gegen Hitlerdeutschland haben diese Hilfe ermöglicht. Darüber hinaus hat die Regierung der UdSSR durch Billigung des Manifestes und durch Erklärungen autorisierter Persönlichkeiten wiederholt erkennen lassen, daß sie im Nationalkomitee ,Freies Deutschland“ und im Bund Deutscher Offiziere mehr sehe als Propagandaeinrichtungen und mehr von ihnen erwarte. Sie hat ihren Willen zum Ausdruck gebracht, im Nationalkomitee und im Bund Deutscher Offiziere die Keimzelle des kommenden freien Deutschland zu sehen, einen politischen Faktor von zukünftiger Bedeutung, einen Bürgen für eine Entwicklung, die eine dauerbafte zuverlässige Zusammenarbeit der UdSSR und des kommenden Deutschland gewährleistet. "31 Seydlitz schlug vor, daß

28 Dazu siehe Gosztony, Stalins fremde Heere, S. 34 ff. , S. $60 \mathrm{ff}$. und S. $101 \mathrm{ff}$.

29 „Aufzeichnung über die Motive zur Gründung des BDO“, von Korfes am 1. 2. 1944 unterschrieben, BArch Abt. Potsdam 90 KO 10/28, Bl. 25.

30 Russische Übersetzung von Seydlitz' Schreiben an Mel'nikov, als Anlage zu dem Brief Berijas an Stalin am 11.3. 1944, GARF 9401/2/64, Bl. 345.

31 „Denkschrift. Wie könnte und sollte die Arbeit des Nationalkomitees „Freies Deutschland“ 
das NKFD von der Sowjetunion öffentlich als deutsche Exilregierung anerkannt und unterstützt werde. Dabei nahm er auch seine schon mehrfach vorgebrachten Pläne zur Aufstellung einer Befreiungsarmee wieder auf, die dem Deutschen Reich nach dem Sturz Hitlers die Besetzung durch alliierte Truppen ersparen, die Befriedung nach innen und die nationale Souveränität nach außen garantieren solle: „Sie [die Befreiungsarmee] soll zum endgültigen Zusammenbruch des Hitlersystems wesentlich beitragen und nach dessen Überwindung auf militärischem Gebiet auch die politische Überwindung und Niederhaltung garantieren. Sie kann auch eine gemischt-alliierte Besetzung mit all ihren Folgerungen - Demarkationslinie, Einflußgebiete - entbehrlich machen." 32

Eine unmittelbare sowjetische Reaktion auf Seydlitz’ Denkschrift blieb aus. Aber am 5. März 1944 gab es eine Besprechung Wilhelm Piecks mit den Generälen in Dombrovo, einem der Spezialobjekte des UPVI. Sowjetische Vertreter waren daran nicht beteiligt ${ }^{33}$. Die Aussprache in Dombrovo war Anlaß zu einer dritten Denkschrift, in der General Lattmann unter direkter Bezugnahme auf Seydlitz' Pläne Gedanken für eine Reorganisation des Nationalkomitees formulierte ${ }^{34}$. Im Kern liefen seine Vorschläge darauf hinaus, den zivilen und militärischen Teil des NKFD zusammenzulegen, das engere Führungsgremium („Präsidium“) auf Pieck, Florin, Seydlitz und Lattmann zu beschränken und die Arbeit des NKFD auf Arbeitsgruppen („Geschäftsführender Aussschuß“) unter der Leitung einzelner Ressortverantwortlicher („Arbeitsspitzen“) zu verteilen. In diesem Zusammenhang bezeichnete Lattman den geschäftsführenden Ausschuß sogar als "Gesamtkabinett“. Vorgesehen waren zehn Ressorts: (1) „Allgemeine Politik und Inneres“; (2) „Wirtschaftsfragen, Handel und Industrie“; (3) „Erziehung, Volksbildung, Jugendpflege und Kultus“; (4) „Sozialpolitik, Arbeitsrecht“; (5) „Ernährung“; (6) „Rechtsfragen (Justiz)“; (7) „Öffentliche Arbeiten und Verkehr“; (9) „Demobilmachung und Volksverteidigung (Wehrmacht)“; (9) „Internationale Politik“; (10) „Organisa-

und des Bundes Deutscher Offiziere verbessert und verstärkt werden, um den Sturz des Hitlerregimes herbeizuführen und ein baldiges Kriegsende zu erzwingen? Wie könnte uns die Regierung der UdSSR dabei helfen? Welches sind die Grundlagen und Möglichkeiten einer für beide Völker gedeihlichen Zusammenarbeit?“, in: Das Nationalkomitee „Freies Deutschland" und der Bund Deutscher Offiziere, S. 287; Hervorhebungen im Original (RGASPI 495/77/35, Bl. 23); kommentierte Edition auch durch Babičenko, „Novaja Germanija ne smožet suščestvovat' bez pomošči SSSR “, S. $48 \mathrm{ff}$.

32 „Denkschrift“, in: Das Nationalkomitee „Freies Deutschland“ und der Bund Deutscher Offiziere, S. 295.

33 Einziger Anhaltspunkt sind die Notizen Piecks (SAPMO-BArch NY 4036/575, Bl. 140-143), in denen die Namen Rodenburg, Lewerenz, Einsiedel, Korfes, Seydlitz, Bechler, Zippel, Kirschhofer und Klein erwähnt werden. Demnach wäre lediglich die militärische Führungsspitze des NKFD/BDO mit einem Vertreter des kommunistischen Teils (Pieck) zusammengekommen.

34 Die Autorenschaft geht lediglich indirekt aufgrund des Stils und der Vorschläge zur Besetzung von Führungspositionen (außer den bisherigen nur noch Lattmann als neue Ernennung) aus dem namentlich nicht unterschriebenen Dokument hervor. Das Memorandum beginnt mit dem Satz „In der Denkschrift des Generals von Seydlitz ...", woraus sich schließen läßt, daß der Autor nicht Seydlitz ist. Korfes und Seydlitz kommen auch aus inhaltlichen Gründen als Autoren nicht in Betracht, da sie in ihren Denkschriften anders argumentieren. Außerdem hat Seydlitz, wie aus dem weiteren Verlauf der Ereignisse hervorgeht, seine am 26. 3. 1944 eingereichte Denkschrift nicht überarbeitet oder durch weitere Vorschläge relativiert. 
tion"35. Im Unterschied zu Seydlitz betonte Lattmann, daß seine Vorschläge sich rein auf innere Angelegenheiten des Nationalkomitees bezögen, die sowjetische Führung daher nicht involviert sei. Auch wenn er damit ganz offensichtlich eventuelle Ansprüche des NKFD auf Anerkennung als Exilregierung zu umgehen versuchte, einen Machtanspruch meldete er dennoch an: „Das bedeutet nicht, daß etwa heute schon eine Art Miniaturkabinett konstruiert werden soll, dessen Aufgaben und Ämter nur auf dem Papier ständen, solange wir noch darum zu kämpfen haben, der Bewegung den Sieg über die bestehende Gewalt zu erkämpfen. (...) Aber das deutsche Volk, dessen Vertrauen wir gewinnen wollen, muß sehen, daß ihm im Nationalkomitee ein verantwortungsbereiter und verantwortungsfähiger politischer Faktor gegenübertritt, der nicht nur einst die effektive Macht haben wird, sondern schon heute die Fähigkeit hat, eine neue glückliche Zukunft für ein demokratisches Deutschland herbeizuführen. "36 Insgesamt ist die Lattmann-Denkschrift als Präzisierung der Seydlitz-Denkschrift aufzufassen. In Reaktion auf das Gespräch mit Pieck versuchte Lattmann offenbar, die politisch heikle Frage der Anerkennung durch die Sowjetunion, auf die Pieck die Generäle eventuell hingewiesen hatte, herunterzuspielen ${ }^{37}$.

Stalin wurde am 11. März vom NKVD über das Seydlitz-Memorandum, nicht aber über die anderen Denkschriften informiert ${ }^{38}$. Obwohl das NKVD seit September 1943 über die Pläne des BDO informiert war, entschloß sich Berija erst jetzt, das Memorandum offiziell an Stalin weiterzureichen. Möglicherweise hing das mit dem zu erwartenden Protest des GlavPURKKA zusammen, das schon bei Mel'nikovs Verhandlungsführung mit den Generälen eingeschritten war. In der Politischen Hauptverwaltung zeigte man sich von den Plänen des BDO überrascht. Manuil'skij teilte Ščerbakov am 11. März mit, daß er im Institut 99 nur durch Zufall auf das $\mathrm{Me}$ morandum gestoßen sei: „Dieses Memorandum habe ich bei dem Vorsitzenden des Nationalkomitees, Freies Deutschland' gefunden. Auf meine Anfrage hinsichtlich dieses Memorandums teilte mir der Kommissar der Staatssicherheit Genosse Mel'nikov mit, daß ihm das Memorandum von Seydlitz überreicht worden sei. Genosse Mel'nikov erklärte außerdem, daß das Seydlitz-Memorandum an Genosse Berija geschickt worden sei und an Genosse Stalin übergeben werde." Eindringlich warnte Manuil'skij vor den diplomatischen Schwierigkeiten, die auf die sowjetische Regierung zukämen, falls das Memorandum den Kriegsverbündeten zur Kenntnis gelangen würde. Denn Seydlitz spiele in seiner Denkschrift auf die Möglichkeit eines deutsch-sowjetischen Sonderfriedens an und gefährde damit die Geschlossenheit der Alliierten ${ }^{39}$. Dieser Eindruck aber durfte gegenüber den Verbündeten auf

35 „Straffere Organisation des Nationalkomitees ,Freies Deutschland' zum Zwecke der Erhöhung der Schlagkraft und des Wirkungsgrades“, RGASPI 495/77/35, Bl. 17-18.

36 Ebenda, Bl. 16 RS.

37 Mit aller gebotenen Vorsicht ließe sich das auch aus den Pieck-Notizen über die Besprechung am 5. 3. 1944 (SAPMO-BArch NY 4036/575, Bl. 142-143) erschließen. Piecks Stichpunkte zum Seydlitz-Memorandum beziehen sich offenbar auf die Auswertung. Die im Notat etwas später folgenden Stichpunkte über ein engeres Führungsgremium und einzelne Ressorts sowie der folgende Absatz über die Neuorganisation der Frontdelegationen, bezögen sich demnach auf in der Diskussion angesprochene Fragen.

38 Berija an Stalin am 11. 3. 1944, GARF 9401/2/64, Bl. 344.

39 Manuil'skij an Ščerbakov am 11.3. 1944, RGASPI 17/128/40, Bl. 45; vgl. Babičenko, „Novaja Germanija ne smožet suščestvovat' bez pomošči SSSR“, S. 49. 
gar keinen Fall entstehen. Das alliierte Verhältnis hatte sich seit der Jahreswende 1943/44 erheblich gebessert, und in der European Advisory Commission (EAC) war begonnen worden, gemeinsam über Nachkriegsdeutschland zu beraten ${ }^{40}$.

Die Überraschung Manuil'skijs über das Seydlitz-Memorandum kann nicht ganz ehrlich gewesen sein. Zeitgleich mit der Berichterstattung an Ščerbakov streute er den Verdacht aus, General Rodenburg und Oberleutnant Huber seien die eigentlichen Autoren des Memorandums ${ }^{41}$. Auch Stalin, der am selben Tag wie Ščerbakov über die Pläne des BDO informiert wurde, waren scheinbar zusammenhangslos mit dem Memorandum die „Auskünfte“ (spravki) über Rodenburg und Huber zugeschickt worden ${ }^{42}$. Die auf diese Weise verbreiteten Verdächtigungen sorgten im weiteren dafür, daß das Memorandum als alleiniger Coup Rodenburgs und Hubers dargestellt werden konnte. So berichtete Manuil'skij zwei Monate später über die Aufdeckung einer ,illegalen faschistischen Organisation“ im BDO, die das „sogenannte Seydlitz-Memorandum" als eine "gezielte Provokation" lanciert habe 43 . Durch diese fadenscheinige, aber nachhaltig wirksame Intrige gelang es Manuil'skij, die Person des BDO-Präsidenten vor der politischen Verantwortung für das Memorandum zu schützen und damit den BDO insgesamt nicht zu diskreditieren ${ }^{44}$.

Eine weitere Realktion auf die Pläne des BDO war die Veröffentlichung der „25 Artikel zur Beendigung des Krieges“ durch das Institut 99. Ursprünglich waren die 25 Artikel unabhängig von den Memoranden von Ulbricht und Herrnstadt erarbeitet worden und sollten als Beschlußvorlage für das NKFD-Plenum dienen. Dann wurden sie aber überstürzt am 5. März 1944 im „Freien Deutschland“ veröffentlicht, denn „Korsun kam dazwischen“45. In Korsun’-Ševčenko bzw. der am Dnepr gelegenen Stadt Čerkassy waren zwei Armeekorps der Wehrmacht von der Roten Armee eingekesselt worden, ohne daß sie sich aus eigener Kraft oder mit Unterstützung von außen hätten freikämpfen können. Zahlreiche NKFD-Bevollmächtigte sowie Seydlitz persönlich versuchten, die verantwortlichen Generäle zur Kapitulation zu bewegen. Die eingeschlossenen Verbände aber wagten trotz aller Warnungen einen Ausbruch aus dem Kessel, der hohe Verluste forderte und das NKFD an der Überzeugungskraft seiner Propaganda zweifeln ließ ${ }^{46}$. Die Ereignisse

40 Die Staatschefs der Alliierten hatten sich auf der Konferenz von Teheran auf die Einsetzung dieses gemeinsamen Planungsstabes geeinigt, der am 14.1. 1944 als „European Advisory Commission" zu seiner ersten Sitzung zusammentrat. Die EAC wurde erst im August 1945 aufgelöst; dazu siehe Kowalski, Die „European Advisory Commission“, S. $261 \mathrm{ff}$.

41 Manuil'skij an Ščerbakov am 11.3. 1944, RGASPI 17/128/40, Bl. 46.

42 Berija an Stalin am 11.3. 1944, GARF 9401/2/64, B1. 377-378. Die „Auskünfte" hatte Mel'nikov bereits am 9.3. 1944 unterschrieben.

43 Manuil'skij an Ščerbakov am 25. 5. 1944, RGASPI 495/77/37, Bl. 26-28; vgl. Reschin, General zwischen den Fronten, S. $169 \mathrm{ff}$.

44 Seydlitz (Stalingrad, S. 346f.) hat diese Lesart bereitwillig aufgenommen. Einsiedel (Tagebuch der Versuchung, S. 133) rückt die Urheberschaft in die Nähe Hubers. Scheurig (Verräter oder Patrioten, S. 133 und ebenda Anm. 108) begegnete diesen Schilderungen mit berechtigtem Mißtrauen, konnte aber wegen des fehlenden Archivzugangs keine allzu deutliche Darstellung geben.

45 „25 Punkte, Disposition Ulbricht, Entwurf Herrnstadt, dann kollektiv umgearbeitet, $3 \mathrm{x}$ im geschäftsführenden Ausschuß, dann plötzlich in Zeitung, Korsun kam dazwischen“, Notizen Piecks vom 26. 3. 1944, SAPMO-BArch NY 4036/ 575, Bl. 148.

46 Seydlitz, Stalingrad, S. 334 ff.; Sie kämpften für Deutschland, S. $229 \mathrm{ff}$. 
in Korsun' waren vermutlich der Auslöser für das Seydlitz-Memorandum, das in der Zeit nach der Rückkehr Seydlitz' von der Front niedergeschrieben wurde. Seydlitz hatte gegenüber Ulbricht beklagt, daß die Gedanken des Nationalkomitees viel zu wenig im Bewußtsein der Wehrmachtssoldaten seien, worüber Ulbricht am 19. Februar Mitteilung an Manuil'skij machte: „Er zog daraus die Schlußfolgerung, daß es notwendig sei, durch Verstärkung der Propaganda die Existenz des NK [ $\mathrm{Na}$ tionalkomitee] zu beweisen, immer wieder zu erklären, was das NK ist und was es will und das Argument, der Bolschewismus bedrohe Europa, zu widerlegen." 47 Nach der Rückkehr von der Front muß Seydlitz grundlegend umgedacht haben, was dann zur Abfassung des Memorandums führte. Noch zwei Wochen zuvor, d.h. vor den Ereignissen in Korsun', hatte er seine Vorschläge auf die Aufstellung eines Kampfverbandes beschränkt ${ }^{48}$. Es sollte zudem nicht übersehen werden, daß die eigene Integrität für das Handeln der Generäle eine große Rolle spielte. Seydlitz hatte sich in persönlichen Briefen an die Kommandierenden der Wehrmacht, an seine Kameraden und Standesgenossen gewandt und empfand daher den Fehlschlag als persönliche Niederlage. Diese Enttäuschung klingt noch in seinen Memoiren nach $^{49}$. Das Seydlitz-Memorandum, ebenso wie die Korfes-Denkschrift, kann daher auch als persönliche Rechtfertigungsschrift interpretiert werden.

Als die 25 Artikel am 5. März veröffentlicht wurden, war das Seydlitz-Memorandum intern bereits im Umlauf. Stalin wurde das „Programm“ der 25 Artikel erst am 20. März vorgestellt, neun Tage nachdem er das Seydlitz-Memorandum erhalten hatte ${ }^{50}$. Die zeitliche Verzögerung einerseits und die Präsentation zweier Programme des NKFD/BDO andererseits lassen darauf schließen, daß Berija die 25 Artikel als neue Plattform des NKFD präsentieren wollte, um damit der Generalsdenkschrift die Brisanz zu nehmen. Bezeichnenderweise wurden die 25 Artikel, im Unterschied zum NKFD-Manifest, dem Gründungsaufruf des BDO und später folgenden Generalsaufrufen, nicht in der sowjetischen Presse veröffentlicht ${ }^{51}$.

Die Politische Hauptverwaltung bemühte sich ebenfalls auf der sogenannten zweiten Armeekonferenz aller Politabteilungen der Fronten im Mai 1944, den durch das Seydlitz-Memorandum ausgelösten Irritationen beizukommen. Obwohl Ščerbakov im Sommer 1943 noch selber von der möglichen Regierungsfunktion des NKFD gesprochen hatte, versuchte er nun, den rein propagandistischen Zweck des Nationalkomitees hervorzukehren: „Das NKFD ist in der gegenwärtigen Etappe des Krieges ein Organ der gegen Hitler gerichteten Propaganda und eine Organisation der Anti-Hitler-Kräfte. Es ist weder mit einer Regierung noch mit militärischen Verbänden gleichzusetzen. (...) Die Aufgabe des NKFD ist und bleibt die politische Propaganda und Agitation im Geiste des ,Manifestes' und der ,25 Artikel'““52 Die „25 Artikel zur Beendigung des Krieges“ bekamen somit für alle Beteiligten die Funktion eines Minimalkonsenses. Sie wurden eine Art „Ersatzpro-

47 Ulbricht an Manuil'skij am 19. 2. 1944, RGASPI 495/77/38, Bl. 54.

48 „Betr. Aufstellung eines militärischen Verbandes“ vom 4. 2. 1944, in: Reschin, Seydlitz, der BDO und die Frage einer deutschen Befreiungsarmee, S. 233; ders., Psevdonim - „svoboda“, S. $146 \mathrm{ff}$.

49 Seydlitz, Stalingrad, S. 344.

50 Berija an Stalin am 20. 3. 1944, GARF 9401/64/64, Bl. 186.

51 Flugblätter des Nationalkomitees Freies Deutschland, S. 185.

52 Zitiert nach Vsevolodov, Vzaimodejstvie politorganov, S. 111. 
gramm", auf dessen Grundlage die Arbeit des NKFD mit Unterstützung durch GlavPURKKA und UPVI fortgesetzt werden konnte. In der Propaganda des NKFD galten sie als die zentrale Grundsatzerklärung nach dem NKFD-Manifest, wobei sich ,in beiden gleich wenige Aussagen zu organisationstechnischen Fragen der Neuordnung [Nacbkriegsdeutschlands] finden, in den 25 Artikeln jedoch eine deutliche Hinwendung zu volksdemokratischen Gedankengängen zu registrieren ist" 53 . Somit präsentierte das NKFD zwar ein „Programm“, das aber in der Formulierung seiner Ziele immer noch so allgemein gehalten war, daß eine Festlegung der sowjetischen Deutschlandpolitik vermieden werden konnte.

Die Auseinandersetzung um das Seydlitz-Memorandum zeigte, daß die Abstimmung zwischen UPVI und GlavPURKKA einerseits sowie die Einigung zwischen $\mathrm{BDO}$ und KPD andererseits nicht gelungen war. Manuil'skij, der die KPD-Führung am 26. März zusammenrief, kündigte eine stärkere Kontrolle der Arbeit des NKFD an und verfügte, daß zur besseren Koordinierung die Zivilsektorsitzungen im Institut 99 regelmäßig einmal die Woche (montags) abgehalten werden sollten ${ }^{54}$. Gleichzeitig wurde durch die Beschlagnahme des Memorandums der Kreis der Mitwisser beschränkt ${ }^{55}$, durch die 25 Artikel die sowjetische Führung beruhigt und mit der Verhaftung Rodenbergs und Hubers diesen die Verantwortung zugeschoben ${ }^{56}$. Für die Zukunft aber mußten die Anleitungsstrukturen gestrafft werden, wobei sich Manuil'skij auf die Koordinierungsfunktion des Instituts 99 besann.

Am 27. März wurde die BDO-Spitze von der operativen Abteilung des UPVI zu einem Gespräch gebeten. Folgt man der Darstellung Einsiedels, so wurde den Generälen die Seydlitz-Denkschrift zurückgegeben mit der - nachweislich falschen Auskunft, man habe es für besser gehalten, sie gar nicht erst an die Vorgesetzten weiterzureichen. Mel'nikov habe Seydlitz die Denkschrift verlesen lassen und ihm eine „regelrechte Gardinenpredigt" gehalten ${ }^{57}$. Ein solch harsches Auftreten legte das UPVI gegenüber dem BDO wahrscheinlich zum erstenmal an den Tag. Vermutlich wurde Seydlitz davon vollkommen überrascht.

53 Petrick, „Freies Deutschland“, S. 146ff., Zitat S. 152.

54 Notizen Piecks über die Besprechung der KPD-Führung (Pieck, Florin, Ulbricht, Ackermann) und Weinert am 26. 3. 1944, in der die Ergebnisse der vorangegangenen Tage zusammengetragen wurden. Picck machte die einzelnen Standpunkte mit "Manuilski“ und „Tscherbakow" kenntlich, SAPMO-BArch NY 4036/575, Bl. 146-150.

55 Manuil'skij an Ščerbakov am 11. 3. 1944, RGASPI 17/128/40, Bl. 47. Es gibt mehrere Fundorte, d.h. mehrere Exemplare des Memorandums: das deutsche, von Seydlitz unterschriebene Original von neun, überwiegend beidseitig beschriebenen Seiten (RGASPI 495/77/35, Bl. 23-31), eine 15-seitige, deutsche Abschrift (GARF 9401/2/64, Bl. 346-355) und eine 18-seitige russische Übersetzung (GARF 9401/2/64, Bl. 356-378 und RGASPI 17/128/40, B1. 48-65). Reschin (Psevdonim - „svoboda“, S. 149 ff.) ediert das Memorandum aus dem Präsidentenarchiv (APRF 3/58/498, Bl. 18-32), bei dem es sich aufgrund der Blattzahl (15 Seiten) um die deutsche Abschrift handeln dürfte. Außerdem ist im Nachlaß Wilhelm Piecks cine detaillierte stichpunktartige Zusammenfassung von der russischen Übersetzung des Memorandums (Pieck vermerkt „18 Seiten“) überliefert, SAPMO-BArch NY 4036/575, B1. 233-238.

56 Über das weitere Schicksal Rodenburgs und Hubers ist wenig bekannt. Huber soll nach einigen Monaten Haft im Offizierslager Grjazovec wieder aufgetaucht sein; Frankenberg, Meine Entscheidung, S. 275.

57 Einsiedel, Tagebuch der Versuchung, S. $133 \mathrm{f}$. Einsiedel schildert diese Episode unter dem Datum „28. März“. Ein Pieck-Notat (SAPMO-BArch NY 4036/575, Bl. 151) hält dieselbe Begebenheit unter dem Datum 27. 3. 1944 fest. 
Im Institut 99 wurde am 29. März beschlossen, die „Arbeit [zu] vereinheitlichen "58. Manuil'skij setzte die Erweiterung des NKFD-Präsidiums auf 18 Personen fest. Die BDO-Spitze (Seydlitz, Korfes, Lattmann, Daniels, van Hooven, Steidle) wurde komplett in das NKFD-Präsidium eingebunden und zu den bisherigen Vizepräsidenten (Hetz, Einsiedel, Emendörfer) kamen fünf Alt-Aktivisten (Hadermann, Reyher, Rücker, Zippel, Klement) hinzu. Die zivilen Mitglieder des Präsidiums (Weinert, Ulbricht, Herrnstadt, Ackermann) waren gleichzeitig Ressortleiter im Institut 99. Um dem Vorschlag Lattmanns, aus dem NKFD das Schattenkabinett einer zukünftigen deutschen Regierung zu machen, die Schärfe zu nehmen, den Vorstellungen der Generäle aber wenigstens ein bißchen entgegenzukommen, sollten die in der Lattmann-Denkschrift vorgeschlagenen Ressorts als Kommissionen des Geschäftsführenden Ausschusses eingesetzt werden ${ }^{59}$. Der durch diese Entscheidung eingeschlagene Weg wird seitens der deutschen Kommunisten nicht sonderlich befriedigt aufgenommen worden sein. Noch am Vortag hatte Ulbricht in einer „Leitungssitzung“ der KPD das Problem zugespitzt: Entweder die Sowjetunion kooperiere mit den Generälen und lasse sich auf Sonderverhandlungen mit Deutschland ein, oder sie pflege das Bündnis mit den Alliierten und lasse das NKFD fallen ${ }^{60}$. Die Politische Hauptverwaltung aber wollte beides. Sie war bestrebt, die Außenwirkung des NKFD eng zu begrenzen, um damit außenpolitischen Schaden für die Sowjetunion zu verhindern. Gleichzeitig wurde dem Nationalkomitee immer noch eine gewisse Rolle zugedacht. Intern signalisierte Manuil'skij daher der KPD, daß ihr „bisheriger Kurs“ richtig sei, er auch beibehalten werden solle, aber „ohne [die] Generäle beiseite zu drücken“61.

An der Haltung Manuil'skijs läßt sich ablesen, daß die sowjetische Seite einen Affront der Alliierten auf jeden Fall vermeiden wollte, aber gleichzeitig das Nationalkomitee als weitere Alternative zu den unterdessen angelaufenen deutschlandpolitischen Planungen der KPD nicht gänzlich aufgab ${ }^{62}$. Die kriegsgefangenen Mitglieder des Nationalkomitees waren - zumindest im Frühjahr 1944 - mitnichten

58 Notizen Piecks über die „Sitzung bei Weinert“ am 29. 3. 1944, bei der Manuil'skij, Burcev, Braginskij, Gerö, Weinert, Ulbricht, Herrnstadt, Ackermann, Pieck und Florin anwesend waren, SAPMO-BArch NY 4036/575, Bl. 151-153.

59 Protokoll der Besprechung bei Manuil'skij am 27. 3. 1944, RGVA/K 88/3/1, Bl. 11; zu den Kommissionen siehe Kapitel VI.2.

60 Notizen Piecks vom 28. 3. 1944, SAPMO-BArch NY 4036/575, Bl. 147: „Gegensatz SU und England, Interesse an Generalen oder Bündnis 3 Großmächte - Voraussetzung Stellung zur Denkschrift, schriftliche Antwort".

61 Ebenda: „Manuilski = bisheriger Kurs richtig, Mobilisierung des Volkes, ohne Generale beiseite zu drücken".

62 Vgl. das Fazit Heiders zur Gründung des NKFD (Gründung des Nationalkomitees, S. 23): „Machtpolitisch betrachtet, dürfte es das Hauptmotiv der sowjetischen Seite gewesen sein, einen möglichst baldigen Frieden um den Preis geringer eigener Opfer zu erreichen und sich zugleich Einflußmöglichkeiten auf die Gestaltung der Nachkriegsordnung in Deutschland, wenigstens aber die Herstellung normaler und friedlicher Beziehungen zwischen beiden Ländern zu sichern. Das galt auch für den Fall eines inneren Umsturzes in Deutschland. Daß dies und nicht etwa dic Absicht, Druck auf die westlichen Verbündeten auszuüben, das Hauptmotiv Stalin gewesen sein dürfte, geht auch daraus hervor, daß die sowjetische Seite im Jahre 1944 nicht nur einmal über Krisensituationen hinweghalf, die zwischen der Führung der KPD im NKFD und dem BDO auftraten.“. 
den "Gesetzen eines politischen Kräftespiels“ unterlegen ${ }^{63}$. Das sowjetische Konzept einer "Anti-Hitler-Bewegung" aus deutschen Kriegsgefangenen aller Dienstgrade und Exilkommunisten blieb bestehen, so wie es im Sommer 1943 als Nationalkomitee „Freies Deutschland“ realisiert worden war.

\section{Manuil'skijs „großdeutsche Linie“}

Nach dem Scheitern der Pläne des BDO, aus dem Nationalkomitee eine deutsche Exilregierung zu bilden, nahm im Frühjahr 1944 Manuil'skij die Fäden wieder stärker in die Hand. Dabei besann er sich auf sein ursprüngliches Konzept, das er im Frühjahr 1942 vorgestellt hatte. Kerngedanke war dabei gewesen, daß die Sowjetunion den Erhalt des Bestandes des Deutschen Reiches zulassen wolle, wenn es dem Komitee gelänge, Hitler zu stürzen und die Beendigung des Krieges herbeizuführen. Manuil'skij hatte nicht auf eine "Zersetzung“ der militärischen Führung, sondern auf die Stärkung der Opposition innerhalb der Wehrmacht und mittelbar in der deutschen Führung gesetzt, um auf diesem Weg zumindest einen Waffenstillstand, wenn nicht sogar Friedensverhandlungen zu erreichen. Der Rat für militärpolitische Propaganda befürwortete eine Werbung für den Erhalt eines souveränen Deutschen Reiches, sofern nur der Sturz Hitlers und ein Waffenstillstand herbeigeführt würden. Weitergehende Pläne hinsichtlich der Zukunft Deutschlands nach dem Krieg waren damit nicht verbunden.

Bei der Vorbereitung zur Gründung des Nationalkomitees, insbesondere bei der Abfassung seines Manifestes, war Manuil'skij der Koordinator im Hintergrund. Der erste Manifestentwurf aus der Feder des nominierten Komiteepräsidenten Weinert war verworfen worden. Weinert forderte darin die Bestrafung der „Kriegsschuldigen", um gleichzeitig nach dem Krieg andere gesellschaftliche Verhältnisse in Deutschland herbeizuführen. Wörtlich hieß es: „Hitler hat bewiesen, daß er sowohl als Staatsmann und Diplomat, wie auch als Stratege nichts anderes ist als ein unfähiger Bankrotteur, ein gewissenloser Glücksspieler, der um der egoistischen Interessen eines Räuberklüngels willen nichts Geringeres aufs Spiel setzte als das Leben, die Freiheit und die Ehre der deutschen Nation. (...) Will das deutsche Volk warten, bis es mit dem Verführer zusammen auf den Schindanger der Geschichte geworfen wird und die Siegermächte ihm einen Frieden diktieren, der zur völligen Ohnmacht und zur Aufteilung unseres Vaterlandes führen muß? Denn es ist kein Zweifel daran, daß dann jedem Deutschen die Verantwortung für die Leiden der überfallenen Völker auferlegt wird, daß die Welt sich gegen jede Wiederholung eines solchen frevlerischen Krieges sichern muß, indem sie Deutschland auf lange Frist entmündigt. Will das deutsche Volk diese Schande auf sich laden? Nein, das kann unser Volk nicht wollen! Es will seine nationale Freiheit und Unabhängigkeit. Und es wird sie haben, wenn es die Fahne der Erhebung gegen den Feind im eigenen Lande ergreift, wenn es den Völkern das Gericht über Hitler und seine Komplizen vor-

63 Fischer, Die Bewegung „Freies Deutschland“, in: Aufstand des Gewissens, S. 445; vgl. ders., Die Bewegung „Freies Deutschland“, in: Der Widerstand gegen den Nationalsozialismus, S. 960. 
wegnimmt! Das ist der Weg der Ehre unseres Volkes!"64 Auch wenn die Entstehungsgeschichte des Gründungsmanifestes des NKFD wegen der schlechten Quellenlage nach wie vor nicht exakt rekonstruiert werden kann, so wird doch durch einen Vergleich mit dem tatsächlich veröffentlichten Manifest klar, daß der Entwurf Weinerts überhaupt nicht den sowjetischen Intentionen entsprach. Seine Vorlage, aus der noch stark die klassenkämpferische Sprache der KPD-Appelle sprach, war vermutlich der Grund dafür, daß neue Autoren beauftragt wurden. Sein Entwurf wurde Dimitrov vermutlich am 1. Juni präsentiert, der darauf eine Neufassung unter der Anleitung von Manuil'skij anordnete 65 .

Anfang Juni 1943 rief Manuil'skij drei ausgewählte Mitarbeiter der 7. Verwaltung - Rudolf Herrnstadt, Alfred Kurella und Oberst Braginskij - zusammen. Sie sollten einen Entwurf für das Manifest des Nationalkomitees schreiben. Inhaltlich gab er vor, daß in dem Manifest der Rückzug der deutschen Truppen aus den besetzten Gebieten oder zumindest ein Waffenstillstand gefordert werden müsse. Das Manifest müsse zum Sturz Hitlers aufrufen und sich für die Überwindung der Schwächen der Weimarer Republik und den Erhalt des Deutschen Reiches einsetzen. In den Beratungen mit den kooperationswilligen Offizieren dürfe von diesen Positionen nicht abgegangen werden, wobei stilistische Änderungen durchaus möglich seien. Manuil'skij legte außerdem fest, daß das Nationalkomitee mit den schwarzweiß-roten Farben des Deutschen Kaiserreiches auftreten solle66. Diese propagandistisch gewollte Reminiszenz an ein starkes, nicht durch die Wirren der Weimarer Republik von innen geschwächtes Deutschland, sorgte bei den Propagandisten des GlavPURKKA für großes Erstaunen ${ }^{67}$. Den nationalkonservativen Gefühlen der Offiziere in NKFD und BDO aber kam dies durchaus entgegen. Infolge der konkreten Anweisungen Manuil'skijs entstand ein Dokument, das in moderaten Formulierungen an das nationale Gewissen des deutschen Volkes appellierte und damit den sowjetischen Vorstellungen sehr viel näher kam als Weinerts Entwurf: „Wenn das deutsche Volk sich jedoch rechtzeitig ermannt und durch seine Taten beweist, daß es ein freies Volk sein will und entschlossen ist, Deutschland von Hitler zu befreien, erobert es sich das Recht, über sein künftiges Geschick selbst zu bestimmen und in der Welt gehört zu werden. Das ist der einzige Weg zur Rettung des Bestandes, der Freiheit und der Ehre der deutschen Nation."68

64 „Manifest des Nationalkomitees Freies Deutschland“ mit dem handschriftlichen Zusatz „variant Vajnerta" vom Juni 1943, SAPMO-BArch NY 4065/12, Bl. 1-8.

65 Vgl. Dimitroff, Tagebücher. Demnach hatte Dimitrov die KPD am 24. 5. 1943 beauftragt, einen Vorschlag für ein antifaschistisches Komitee auszuarbeiten. Am 1.6. 1943 notierte Dimitrov: „Pieck und Ulbricht - wir sind eine Reihe von Fragen durchgegangen, die mit der Arbeit unter den Kriegsgefangenen und den Parteien im Land zusammenhängen." Und schließlich wurde am 11.6. 1943 vermerkt: „Manuilski und Pieck - haben den Entwurf für den Beschluß zur Schaffung des antifaschistischen deutschen Komitees ,Freies Deutschland" vorgelegt."

66 Müller-Enbergs, Der Fall Rudolf Herrnstadt, S. 39 f.; ders., Das Manifest des NKFD, S. 94 f. Die Schilderung der Entstehungsgeschichte des NKFD-Manifestes geht zurück auf eine von Max Emendörfer angefertigte Niederschrift der Erinnerungen Herrnstadts (SAPMO-BArch SgY 30/2083), die wegen ungeklärter Rechtsansprüche für die Bearbeitung nicht zur Verfügung stand.

67 Leonhard, Revolution, S. 280; vgl. Mayenburg, Blaues Blut und rote Fahnen, S. 305 f.

68 Manifest des NKFD vom 13. 7. 1943, in: Das Nationalkomitee „Freies Deutschland“ und der Bund Deutscher Offiziere, S. 266. 
Manuil'skij trug bereits bei der Vorbereitung zur Gründung des NKFD dafür Sorge, daß für die Akzeptanz des NKFD durch die Generäle die notwendigen Grundvoraussetzungen geschaffen wurden. Es lag offenbar nicht in seiner Hand, den Zeitpunkt der Gründung des Nationalkomitees von dem Erfolg der Vorbereitungen abhängig zu machen, so daß die Chronologie der Umsetzung - Gründung des Nationalkomitees und erst nachträgliche Einbeziehung der Generäle - umgekehrt wurde. Die im Frühjahr 1944 folgende Diskussion mit den Generälen um die Frage einer Exilregierung wurde durch das Vorpreschen des UPVI (Mel'nikov) provoziert, das Manuil'skij nicht verhindern konnte. Zudem stand bei der Gründung des Nationalkomitees im Juli 1943 dessen außenpolitische Wirkung im Mittelpunkt des Interesses.

Die Verbündeten der Sowjetunion waren von der Gründung des Nationalkomitees vollkommen überrascht. Die sowjetische Verhandlungsbereitschaft gegenüber einer deutschen Regierung warf bei den Westalliierten Fragen auf, zumal sie sich im Sommer 1943 bereits deutlich für eine bedingungslose Kapitulation Deutschlands ausgesprochen hatten. Mit „leichtem Unbehagen“ wurde konstatiert, daß aus den Formulierungen des Manifestes nicht genau hervorging, wo die Grenzen Nachkriegsdeutschlands liegen sollten. Auch die offensichtliche Bereitschaft der Sowjetunion, im Falle eines vorzeitigen Friedensschlusses den Fortbestand der Wehrmacht zu akzeptieren, wurde „negativ vermerkt ${ }^{\text {“ } 69}$. Stalin spielte gegenüber den Alliierten die Bedeutung des NKFD für die sowjetische Deutschlandpolitik herunter. Einerseits konnte er zufrieden sein, denn nun erst unternahmen die Verbündeten konkrete Schritte, um zu gemeinsamen Gesprächen zu gelangen, wie sie dann erstmals auf der Moskauer Außenministerkonferenz im Oktober 1943 erfolgten ${ }^{70}$. Andererseits rief die Ungewißheit der Koalitionäre unkontrollierbare Spekulationen hervor, worauf das Volkskommissariat für Äußere Angelegenheiten noch vor Beginn der Moskauer Außenministerkonferenz hinwies: „In einigen ausländischen Kreisen ist der Eindruck entstanden, daß wir die Absicht haben, mit Deutschland bedeutend nachsichtiger umzugehen als die übrigen Alliierten, wobei sie uns in dieser Hinsicht die unsinnigsten Nachkriegspläne zuschreiben."71 So gesehen waren die Beschwichtigungen Stalins dringend notwendig, um das Vertrauensverhältnis nicht restlos zu zerstören. Während der Moskauer Konferenz versicherte er dem britischen Außenminister Eden: „Das deutsche Komitee ist ein Propagandaorgan. (...). Natürlich, in dem deutschen Komitee sind Leute, die davon träumen, daß sie das Schicksal Deutschlands entscheiden werden. Aber man muß daran erinnern, daß ein ernstzunehmender Staat nicht gemeinsame Sache mit Kriegsgefangenen machen wird." 72

Trotz aller Beteuerungen gegenüber den Verbündeten ging es der sowjetischen Führung mit dem Nationalkomitee dennoch um mehr als eine effektive psychologische Kriegführung. An den internen Auseinandersetzungen mit der Exilleitung der Kommunistischen Partei Österreichs wird deutlich, daß die sowjetische Führung

69 Bungert, Das Nationalkomitee und der Westen, S. $36 \mathrm{f}$.; vgl. auch Scheurig, Verräter oder Patrioten, S. $76 \mathrm{ff}$.

70 Bungert, Das Nationalkomitee und der Westen, S. 114.

71 Litvinov an Molotov am 9. 10. 1943, in: SSSR i germanskij vopros, tom I, S. 287.

72 Zitiert nach SSSR i germanskij vopros, tom I, S. 664, Anm. 70; vgl. Fischer, Sowjetische Deutschlandpolitik, S. $66 \mathrm{f}$. 
bis zum Herbst 1944 an der Option festhielt, den Fortbestand des Großdeutschen Reiches hinzunehmen, wenn es denn zu einem Waffenstillstand käme. Schon lange war den österreichischen Kommunisten die Haltung sowjetischer Funktionäre bekannt, „die Okkupation Österreichs durch Hitler stillschweigend als ein geschichtliches post factum, als Anschluß anzuerkennen". $\mathrm{Zu}$ dieser Überzeugung kam die österreichische Exilkommunistin Ruth von Mayenburg bereits Anfang 1942 in einer langen Diskussion mit Manuil'skij ${ }^{73}$. Als Manuil'skij mit der Gründung des NKFD eine Propagandastrategie entwarf, die den Bestand eines souveränen Deutschen Reiches in den Mittelpunkt ihrer Argumentation stellte, war der Konflikt mit den österreichischen Kommunisten vorprogrammiert. Denn als es nach der Auflösung der Komintern um die Schaffung nationaler antifaschistischer Komitees unter Einbeziehung Kriegsgefangener ging, hatte Dimitrov auch die KPÖ angesprochen $^{74}$. Weisungsgemäß unterbreitete KPÖ-Chef Koplenig Mitte Juni 1943 einen Richtlinienentwurf für die Etablierung einer österreichischen Antifa: „Die politische Propaganda unter den Österreichern wird in der Richtung der Förderung und Unterstützung der österreichischen Freiheitsfront geführt, die sich den Kampf für die Vertreibung der deutsch-faschistischen Okkupanten und die Wiederherstellung eines freien und unabhängigen Österreich zur Aufgabe stellt. Es ist daher nicht zweckmäßig, daß österreichische Kriegsgefangene Aufrufe für ein freies Deutschland unterschreiben, weil dadurch die Tatsache der Okkupation Österreichs verwischt, ja sogar anerkannt wird. Propaganda unter den Österreichern oder von Österreichern für ein freies Deutschland kann nur Verwirrung stiften und in gewissem Sinne den großdeutschen profaschistischen Elementen Vorschub leisten."75 Klang in dieser Vorlage bereits das deutsch-österreichische Konkurrenzverhältnis an, so hatte sich die sowjetische Führung unterdessen vollständig auf eine "großdeutsche Linie" des Nationalkomitees festgelegt.

Dimitrov ignorierte die von der KPÖ vorgelegten Vorschläge. Vorsichtshalber wurde Koplenig für die Dauer der Gründungsveranstaltung des Nationalkomitees der Zutritt zum Lager Krasnogorsk verwehrt ${ }^{76}$. Dem solchermaßen düpierten Koplenig blieb lediglich der vehemente Protest, als am 12. Juli in Krasnogorsk das Manifest des NKFD feierlich und zudem auch noch von einem österreichischen Offizier (Major Stößlein) unterschrieben wurde: „Die Ursache der einander widersprechenden Direktiven, der steigenden Verwirrung in bezug auf die österreichische Frage in den Lagern ist unserer Meinung nach darin zu suchen, daß Genosse Manuilsky in der österreichischen Frage eine grundsätzlich andere Linie verfolgt als die österreichische Partei. Die grundsätzliche andere Auffassung, die ihrem Inhalt nach eine großdeutsche ist, überträgt sich auf den Apparat der Pur [GlavPURKKA]

73 „Manuilsky jedoch war kein Verfechter der österreichischen Nation - sosehr er uns als ,charmante Abart der Deutschen' mochte -, und das konnte für die Einstellung und politischen Richtlinien der Bolschewistischen Partei der SU [Sowjetunion] zu dieser Frage von großer aktueller Bedeutung sein.", Mayenburg, Blaues Blut und rote Fahnen, S. $291 \mathrm{f}$.

74 Dimitroff, Tagebücher, Eintrag vom 24. 5. 1943.

75 Entwurf einer Instruktion an die Leiter der Kriegsgefangenenlager, als Anlage zu dem Brief Koplenigs an Dimitrov vom 18. 6. 1943, RGASPI 495/77/27, Bl. 146-147.

76 Koplenig an Dimitrov am 12.7. 1943 und handschriftlicher Vermerk Dimitrovs auf dem Brief, den Zutritt zum Lager Krasnogorsk erst nach dem 15. Juli zu erlauben, RGASPI 495/77/27, Bl. 170. 
und die Instrukteure und kommt in den konkreten Anweisungen zum Ausdruck."77 Manuil'skijs Reaktion auf Koplenigs Vorwürfe erfolgte prompt. Telefonisch wies er den KPÖ-Chef an, sich an die vorgegebene sowjetische Linie zu halten. Am 17. Juli mußte sich Koplenig in einem kleinlauten Brief an Manuil'skij entschuldigen: „Ihre mir telefonisch übermittelte Antwort auf meinen Brief hat mich sehr schwer getroffen. Ich fühle die Notwendigkeit, Ihnen zu versichern, daß es in keiner Weise in meiner Absicht lag, mich in verletzender und anmaßender Weise an Sie zu wenden. Ich fühle diese Notwendigkeit um so mehr, als ich nach Ihrer Antwort und der neuerlichen Durchsicht des Briefes zu der Überzeugung gekommen bin, daß dieser Brief von Ihnen so verstanden werden konnte, um so mehr, als er, wie aus Ihrer Mitteilung hervorgeht, von falschen Voraussetzungen ausgegangen ist."78 Abgesehen davon, daß dieser Briefwechsel eines der wenigen belegbaren Beispiele für die Art der Konfliktbereinigung innerhalb des sowjetischen ZK-Apparates ist, zeigt der Zwischenfall, daß der Rat für militärpolitische Propaganda im Sommer 1943 trotz der mit der Auflösung der Komintern proklamierten Unterstützung des nationalen Freiheitskampfes der kommunistischen Parteien die Annexion Österreichs zugunsten des Erfolges des NKFD überging. Die KPÖ mußte sich den Anweisungen Manuil'skijs beugen.

Nach der Gründung des BDO und dessen Beitritt zum Nationalkomitee, wurde Mitte September 1943 im Institut 99 noch einmal die Sprache auf die Annexion Österreichs gebracht. Aber der eingeschlagene Kurs wurde nicht geändert. Österreichische wie deutsche Kriegsgefangene sollten in der Bewegung „Freies Deutschland“ organisiert werden: „Stellung zur österreichischen Frage, ob Anschluß oder Selbständigkeit steht jetzt zur Diskussion, Anschluß an Bewegung Freies Deutschland, Eintritt in NKFD, in einer kleinen Kommission in Pur [GlavPURKKA]."79 Es ist daher gut möglich, daß in den Verhandlungen zur Gründung des BDO den Generälen tatsächlich der Erhalt des Deutschen Reiches in den Grenzen von 1938, d. h. unter Einschluß Österreichs, zumindest aber eine den (groß)deutschen Interessen entsprechende Grenzregelung angeboten wurde ${ }^{80}$.

Eine Änderung der "großdeutschen Linie“ hätte nach Abschluß der Moskauer Konferenz erfolgen können, zumal sich die Außenminister der Alliierten gemeinsam für eine Wiederherstellung der Souveränität Österreichs ausgesprochen hatten. Es ist zwischen Dimitrov und Koplenig auch zu einer erneuten Besprechung gekommen, aber die am 17. November 1943 erneut eingereichten Vorschläge der KPÖ für eine eigenständige österreichische Antifa wurden dann doch wieder ignoriert $^{81}$. Zu der Frage eines souveränen Österreichs äußerte sich das Nationalkomitee

77 Koplenig an Dimitrov und Manuil'skij am 13. 7. 1943, RGASPI 495/74/20, Bl. 6-7.

78 Koplenig an Manuil'skij am 17.7. 1943, RGASPI 495/74/20, BI. 12; ebenda, Bl. 11 eine gleichlautende Entschuldigung Koplenigs an Dimitrov ebenfalls vom 17. 7. 1943.

79 Notizen Piecks über „Leitungssitzung 20.9. 1943, im Büro des NK [Nationalkomitees]“, SAPMO-BArch NY 4036/498, Bl. 95.

80 Vgl. Gerlach, Die Werbung der Generale, S. 96. Die beteiligten Generäle dagegen sind in ihren Erinnerungen sehr viel vorsichtiger: Daniels (Niederschrift, S. 97) erinnert sich, daß Mel'nikov betont habe, "die Grenzen sollten nach deutschen Interessen geregelt werden“. Seydlitz (Stalingrad, S. 286) spricht von einem „Reich in den Grenzen von 1937“ und fügt hinzu: „Die österreichische Frage wurde meiner Erinnerung nach dabei nicht erwähnt“.

81 „Aufgrund unserer Aussprache sende ich Ihnen unsere Vorschläge zur Verstärkung der Arbeit unter den österreichischen Kriegsgefangenen“, Koplenig an Dimitrov am 17.11. 1944, 
erst nach der alliierten Konferenz von Teheran. Dennoch war nicht die Rede von getrennten Wegen einer deutschen und einer österreichischen Bewegung, sondern es wurde demonstrativ der gemeinsame Kampf gegen Hitler betont: „Das Nationalkomitee ,Freies Deutschland' unterstützt den Freiheitskampf des österreichischen Volkes und fühlt sich ihm in dem gemeinsamen Kampf gegen Hitler und sein System brüderlich verbunden. "82 Die kurz darauf, Anfang März 1944, veröffentlichten „25 Artikel zur Beendigung des Krieges“ nahmen überhaupt keinen Bezug auf die Souveränität Österreichs. Statt dessen will darin das NKFD das Erbe des Deutschen Reiches übernehmen (Artikel 11) und fordert den geschlossenen Kampf gegen Hitler „unter der Fahne des Nationalkomitees“ (Artikel 21) ${ }^{83}$.

Bis zum Herbst 1944 basierte die politische Arbeit unter den deutschsprachigen Kriegsgefangenen ausschließlich auf dem "großdeutschen“ Programm des Nationalkomitees, auch wenn gemeinhin die alliierten Konferenzbeschlüsse von Teheran als „zweite Etappe“ des Nationalkomitees angesehen werden ${ }^{84}$. Da die operative Arbeit des UPVI jedoch eine Angelegenheit des NKVD und somit formal im Bereich der Innenpolitik angesiedelt war, mußte sie nicht zwangsläufig auf außenpolitische Vereinbarungen der Sowjetunion reagieren ${ }^{85}$. Ebenso wie der BDO nach der durch das Seydlitz-Memorandum ausgelösten Krise im Nationalkomitee seinen, obgleich geschwächten, Einfluß beibehielt, so änderte sich die politische Arbeit unter den kriegsgefangenen Wehrmachtsoldaten trotz alliierter Absprachen nicht. Noch Ende Oktober 1944 kam es im Offizierslager Nr. 150 wegen der Frage eines eigenständigen österreichischen Antifa-Aktivs zwischen deutschen und österreichischen Parteifunktionären zum offenen Streit. Gustav Sobottka, KPD-Funktionär und NKFD-Mitglied, rügte den österreichischen Kommunisten Willi Fink, daß „durch diese österreichische Tätigkeit die antifaschistische Einheit gestört und den Faschisten geholfen werde"86. Ein Gedächtnisprotokoll zweier (österreichischer) Offiziere beschrieb Sobottkas Auftreten in dieser Diskussion: „Herr Sobottka erörterte die Aufgaben, die seiner Meinung nach die Österreicher hatten. Er betonte, daß gerade in der Arbeiterschaft starke Strömungen für einen Anschluß an Deutschland seien, daß solche Bestrebungen großdeutscher Art in der Geschichte der österreichischen Arbeiterbewegung schon vor 1866 nachweisbar seien und daß die anwesenden Österreicher kein Urteil darüber hätten, in welchem Maße die Stimmung in Österreich heute für die Selbständigkeit sei. "87 In seiner späteren Stellungnahme gegenüber Pieck bestätigte Sobottka diese Darstellung und berief sich auf die Beschlüsse des NKFD vom Dezember 1943 sowie die dementsprechenden Richtlinien des UPVI, die eine eigenständige österreichische Antifa nicht vor-

RGASPI 495/77/27, Bl. 192; ebenda, Bl. 193: „Vorschläge zur Verstärkung der Arbeit unter den österreichischen Kriegsgefangenen".

82 Zitiert nach Weinert, Nationalkomitee, S. 91.

83 FD Nr. 10/1944 vom 5. 3. 1944, S. 1; ediert in: Scheurig, Verräter oder Patrioten, S. 193 ff.; Sie kämpften für Deutschland, S. $171 \mathrm{ff}$.

84 Sywottek, Deutsche Volksdemokratie, S. $134 \mathrm{ff}$.

85 Vgl. Laufer/Kynin in der Einleitung zu SSSR i germanskij vopros, tom I, S. 36.

86 „Kurze Darstellung der Vorkommnisse im Lager 150“ durch Willi Fink, SAPMO-BArch NY 4036/572, Bl. 278.

87 Von zwei österreichischen kriegsgefangenen Offizieren angefertigtes Gedächtnisprotokoll der Diskussion vom 24. 10. 1944, SAPMO-BArch NY 4036/572, Bl. 280. 
sähen ${ }^{88}$. Offenbar galten für die Politinstrukteure in den Kriegsgefangenenlagern im Oktober 1944 noch derartige Anordnungen, und Sobottka befand sich damit formal im Recht. Er konnte dabei nicht wissen, daß genau zu dem Zeitpunkt seines Auftretens im Offizierslager in Moskau die Entscheidung über die Zulassung einer eigenständigen österreichischen Antifa gefallen war.

Anfang August 1944 wurde die KPÖ abermals wegen einer eigenständigen österreichischen Antifa bei Dimitrov vorstellig. Koplenig monierte, daß österreichische Kriegsgefangene sich nur in der Bewegung „Freies Deutschland“ engagieren könnten, was zunehmend auf Widerstand stoße: „Nicht nur von den österreichischen Soldaten, sondern auch von den Offizieren wird der entschiedene Wunsch nach einer besonderen nationalen Zusammenfassung der Österreicher unabhängig vom deutschen Nationalkomitee geäußert. Dies um so mehr, als heute in den Lagern erklärt wird, daß die antifaschistische Gesinnung nur durch das Bekenntnis zum deutschen Nationalkomitee bzw. den Beitritt zum Bund deutscher Offiziere zum Ausdruck gebracht werden kann. Damit wird nicht nur der besondere nationale Charakter des österreichischen Freiheitskampfes verwischt, sondern auch ein politisch-moralischer Druck auf die österreichischen Gefangenen ausgeübt in einer Richtung, die im Widerspruch steht zur allgemeinen Linie in der österreichischen Frage. " 89 Der erneute Vorstoß Koplenigs, der mit seinen Vorschlägen bereits zweimal gescheitert war, ist im Zusammenhang mit den alliierten Nachkriegsplanungen in der European Advisory Commission zu sehen. Dimitrov, der in dieser Hinsicht wahrscheinlich besser über den Stand der Beratungen informiert war als die KPÖ, hätte Koplenig auf eine sich anbahnende Änderung in der sowjetischen Haltung hinweisen können. Am 25. August legte die sowjetische Regierung in der EAC ihre Haltung zu der alliierten Kontrolle Deutschlands - ohne Österreich - nach dem Krieg dar ${ }^{90}$. Kurz darauf kam es zu einem Treffen zwischen Dimitrov und Koplenig91, auf dem offenbar die Gründung eines eigenständigen „Antifaschistischen Komitees österreichischer Kriegsgefangener" zugestanden wurde. Denn nachdem am 12. September in der EAC die endgültige Vereinbarung über die Besatzungszonen in Deutschland geschlossen worden war ${ }^{92}$, reichte Koplenig am 20. September unter Bezugnahme auf die drei Wochen zurückliegende Besprechung Kadervorschläge für die Bildung des österreichischen Komitees ein ${ }^{93}$.

Die Vorschläge der KPÖ gingen zur weiteren Bearbeitung an das Institut 99. Dort war kurz zuvor über die zukünftigen Aufgaben des NKFD beraten worden, was auf eine Änderung in der politischen Grundhaltung hinwies ${ }^{94}$. Dimitrov

88 Sobottka an Pieck am 19. 11. 1944, SAPMO-BArch NY 4036/572, Bl. 281-283 RS.

89 Koplenig an Dimitrov am 2. 8. 1944, RGASPI 495/74/22, Bl. 56.

90 „Memorandum zu der Frage des alliierten Kontrollmechanismus in Deutschland“ vom 25. 8. 1944, in: SSSR i germanskij vopros, tom I, S. 530.

91 Auf dem Brief Koplenigs an Dimitrov vom 2. 8. 1944 befindet sich ein handschriftlicher Vermerk von Dimitrovs Sekretär Mirov über ein 'Treffen Dimitrovs mit Koplenig am 30. 8. 1944, RGASPI 495/74/22, Bl. 56.

92 Dazu siehe Laufer, Die UdSSR und die Zoneneinteilung Deutschlands, S. 324 ff.; Deuerlein, Die Präjudizierung der Teilung Deutschlands, S. 358 ff.; Fischer, Sowjetische Deutschlandpolitik, S. $75 \mathrm{ff}$.

93 Koplenig an Dimitrov am 20.9. 1944 nebst Anlagen, RGASPI 495/74/22, Bl. 63-65.

94 „Arbeitsplan des Nationalkomitees in nächster Zukunft“, Protokoll des Instituts 99 vom 18. 9. 1944, RGASPI 495/77/46, BI. 21. 
berichtete an die sowjetische Führung, mit der vermutlich das weitere Vorgehen abgestimmt wurde ${ }^{95}$. Unterdessen hatte TASS am 28. September die Ergebnisse der EAC-Verhandlungen veröffentlicht ${ }^{96}$, und am 2 . Oktober beschloß der wöchentlich im Institut 99 zusammenkommende Führungskreis, die Mitglieder des NKFD im Lager Lunevo („Objekt Nr. 15“) auf die neue Linie einzustimmen: „Am Mittwoch, den 11. Oktober soll eine Vollsitzung des Nationalkomitees stattfinden, die sich mit den Aufgaben des Nationalkomitees in der Endphase des Krieges beschäftigen wird. Am Sonnabend, den 7. d. M. soll in Objekt 15 ein Vortrag eines österreichischen Genossen und am Sonnabend, den 14. d. M. eines sudetendeutschen Genossen über das Thema ,Die Sudetendeutschen in der Tschechoslowakischen Republik' stattfinden. Außerdem sollen von Seiten des NK [Nationalkomitees] an die Lagerleitungen Anweisungen ergehen, in denen die österreichischen und sudetendeutschen Kriegsgefangenen, die bisher der Bewegung „Freies Deutschland“ angehörten, aufgefordert werden, sich ihrer Bewegung anzuschließen. "97 Am 10. Oktober holte Dimitrov die Bestätigung von NKVD-Chef Berija ein, die österreichischen Kriegsgefangenen aus der Bewegung „Freies Deutschland“ auszugliedern und ihnen die Gründung eines "antifaschistischen Büros" zu gestatten. Das Büro solle „rein internen Charakter" tragen, d.h. es würde keine Gründungskonferenz, kein öffentliches Auftreten und keine Beteiligung von KPÖ-Funktionären geben. Die Aktivitäten seien vornehmlich auf das Kriegsgefangenenlager Krasnogorsk zu beschränken und stünden unter der Kontrolle des Instituts 9998. Am 12. Oktober folgte Molotovs Zustimmung99.

Das NKVD ordnete die Trennung von deutscher und österreichischer Antifa an, überließ die konkrete Umsetzung aber dem Institut 99, das in Absprache mit der operativen Abteilung des UPVI die von Koplenig eingereichten Kadervorschläge prüfte ${ }^{100}$. So kam es am 18. Oktober zu einer Absprache zwischen UPVI, KPÖ und BDO, auf der wahrscheinlich das weitere Vorgehen festgelegt wurde ${ }^{101}$. Über diese Absprachen waren jedoch die KPD und auch die einzelnen Lagerverwaltungen des UPVI noch nicht informiert, so daß es im Oktober 1944 im Lager Nr. 150 noch zu den oben geschilderten Auseinandersetzungen zwischen Fink und Sobottka kommen konnte ${ }^{102}$. Das „Antifaschistische Büro österreichischer Kriegsgefangener“

95 Auf dem Brief Koplenigs an Dimitrov vom 20. 9. 1944 befindet sich Dimitrovs Anweisung vom 23. 9. und Mirovs Bearbeitungsvermerk über einen Brief an Berija vom 10.10. 1944, RGASPI 495/74/22, Bl. 63.

96 TASS-Erklärung vom 28. 9. 1944, in: SSSR i germanskij vopros, tom I, S. $548 \mathrm{ff}$.

97 Beschlußprotokoll des Instituts 99 vom 2. 10. 1944, RGASPI 495/77/46, Bl. 23.

98 Dimitrov an Berija am 10. 10. 1944, RGASPI 495/74/21, Bl. 93-94.

99 Berija an Molotov am 12. 10. 1944, GARF 9401/2/70, Bl. 14; ebenda der positive Bescheid, der noch am selben Tag durch handschriftlichen Vermerk Molotovs am Rand des Schreibens erfolgte.

100 Kozlov an Dimitrov am 27. 10. 1944, RGASPI 495/74/22, Bl. 76-78.

101 Berija an Dimitrov am 14. 10. 1944, RGASPI 495/77/31, Bl. 229; ebenda Dimitrovs Anweisung vom 14. 10. 1944 und Manuil'skijs Ausführungsvermerk über ein Trefffen Koplenigs mit Petrov am 18. 10. 1944.

102 „Zur Begründung der selbständigen österreichischen Organisation in den Kriegsgefangenenlagern führte Fink an, daß in Moskau Besprechungen mit General Petrow, den deutschen Generalen und dem Genossen Koplenik stattgefunden hätten, bei denen unsere Frage erörtert worden und die eigene österreichische Organisation festgelegt sei.", Sobottka an Pieck am 19. 11. 1944, SAPMO-BArch NY 4036/572, Bl. 282-283. 
nahm seine Tätigkeit erst Anfang 1945 auf, obwohl die Auswahl der Mitglieder und die Aufgabenbeschreibung des Büros Anfang November 1944 abgeschlossen waren ${ }^{103}$. Zwar begann das Institut $99 \mathrm{im}$ Dezember 1944 mit der Herausgabe der „Mitteilungen für die österreichischen Antifaschisten“, aber erst im März 1945 wurde die operative Abteilung des UPVI um die Bestätigung zur Entsendung von Bevollmächtigen des Büros in die Lager gebeten. Vermutlich entfaltete das Büro dort erst nach dem Kriegsende eine gewisse Aktivität ${ }^{104}$.

Manuil'skijs "großdeutsche Linie“ bewirkte, daß während des Krieges die gesamte politische Arbeit unter den Wehrmachtssoldaten auf das Nationalkomitee „Freies Deutschland“ ausgerichtet wurde. Erst nachdem eine alliierten Einigung über die Besatzungszonen in Deutschland erzielt worden war, wurde die Tätigkeit des NKFD auf Deutschland in den Grenzen von 1937, d.h. ohne Österreich, eingeschränkt. Nun begann die innersowjetische Diskussion über die Politik im Nachkriegsdeutschland, zu der die KPD im Herbst 1944 ihr deutschlandpolitisches Programm vorlegte.

\section{Volksfrontstrategie der KPD}

Die politische Arbeit unter den deutschen Kriegsgefangenen in der Sowjetunion stützte sich von Anbeginn an stark auf die Zuarbeit der KPD. Aus deren Sicht war die Beteiligung deutscher Kommunisten am Nationalkomitee „Freies Deutschland“ die Fortsetzung des Volkskampfes unter den spezifischen Bedingungen des Krieges und der Emigration, in dem sich das ganze deutsche Volk ungeachtet politischer Anschauungen zum Sturz Hitlers zusammenschließen müsse ${ }^{105}$. In der historiographischen Selbstdarstellung fand dieser Zusammenschluß unter der Führung der KPD statt ${ }^{106}$, was von den Kommunisten zweifelsohne erstrebt wurde, sich aber in der Realität immer auf die von sowjetischer Seite eingeräumten Spielräume beschränkte.

Die Gründungsveranstaltung des NKFD war ganz im Sinne der KPD so inszeniert worden, daß der Eindruck eines alle Schichten des deutschen Volkes umfassenden Komitees entstehen konnte. Parteimitgliedschaft wurde nicht erwähnt. Wilhelm Pieck zum Beispiel firmierte als „Reichstagsabgeordneter, Berlin“. Auf der Gründungsveranstaltung traten die Unterzeichner des Manifestes unter Hervorhebung ihrer beruflichen Tätigkeit als Redner auf. Auch wurden ihre über ganz Deutschland verstreuten Heimatorte genannt, so daß der Eindruck eines wahren

103 Siehe Kandidatenlisten, von Kozlov am 27.10. 1944 an Dimitrov, RGASPI 495/74/22, Bl. 76-78; „Hauptziele und Aufgaben des Antifaschistischen Büros österreichischer Kriegsgefangener" vom 1.11. 1944, ebenda 495/77/31, Bl. 230.

104 Siehe Nr. 1 der Mitteilungen, SAPMO-BArch NY 4036/551, Bl. 19-33; Kozlov an Kobulov am 6. 3. 1945, RGVA/K 4p/5/20, Bl. 128; vgl. Abteilungen des Instituts 99 ab 1946, RGASPI 17/128/1150, Bl. 4; siehe auch Gosztony, Stalins fremde Heere, S. 125 ff.; Frick, Umdenken hinter Stacheldraht.

105 Vgl. Sywottek, Deutsche Volksdemokratie, S. $127 \mathrm{ff}$.

106 Idealtypisch: Löwel, Die Gründung des NKFD, S. $613 \mathrm{ff}$.; Auseinandersetzung mit der Darstellung des NKFD in der DDR: Diesener, Die Bedeutung des Nationalkomitees „Freies Deutschland“, S. 17 ff.; Heider, Das NKFD und der BDO in der Historiographie der DDR, S. 161. 
„Volkskomitees“ entstand. Hauptmann Fleischer („Volkswirtschaftler“) sprach über die „Deutsche Wirtschaft unter Hitler". Die Offiziere Hadermann und Rücker („Studienräte“) wandten sich "Gegen die Pseudo-Wissenschaft der Naziclique“. Für die Jugend sprach Soldat Keßler („Maschinenschlosser“), kirchliche Belange wurden von dem Gefreiten Eschborn („stud. theol., Mitglied des Ordens vom Herzen Jesu“) und dem Unteroffizier Klein („evangelischer Pastor“) behandelt. Klein, der aus bäuerlichen Verhältnissen kam, sprach über „Geknechtete Bauern, geknechteter Glaube. Von der Not und dem Kampf des evangelischen Bauernvolkes" und demonstrierte damit abermals den Gedanken des alle Schichten umfassenden „Volkskomitees“. Zudem referierte der Gefreite Helmschrott („Bauer“) über das "Deutsche Bauerntum am Rande des Abgrunds"107. Sowohl die Themen als auch die Referenten boten Anknüpfungspunkte für die Bildung von Arbeitsgruppen. Mit dem Wissen um die späteren Diskussionen im BDO könnte man auch von einem Ansatz für die Bildung eines Schattenkabinetts sprechen. Aber durch den Zusammenschluß von NKFD und BDO verschob sich der bei der Gründung des Nationalkomitees gesetzte Akzent enorm zugunsten der Haltung der Offiziere.

Der Bund Deutscher Offiziere genoß vom Zeitpunkt seiner Gründung an die volle Unterstützung von UPVI und GlavPURKKA, was zu einiger Verwirrung unter den deutschen Kommunisten führte. Die konstituierende Versammlung des Offiziersbundes erfolgte anlog zu der NKFD-Gründung, aber dieses Mal traten die Vortragenden nur unter Nennung ihres Dienstgrades auf. Dabei spiegelte das von Oberst van Hooven gehaltene Grundsatzreferat nahezu prototypisch die nun vorherrschende Herangehensweise an gesellschaftspolitische Fragen wider. Unter der Überschrift „Deutschlands Lage fordert den Entschluß der Wehrmacht“ wurden in Form von Lageanalysen („militärische, politische, wirtschaftliche Lage“) Aussagen über alle Bereiche des öffentlichen Lebens getroffen ${ }^{108}$. Der BDO verstand sich dabei als eine nach ständischen Merkmalen organisiertc Sammlungsbewegung von Offizieren, die als geschlossene Korporation für die Belange Deutschlands eintrat. Für Fachkommissionen war da kein Platz. Einzige Gemeinsamkeit zu der Festveranstaltung des NKFD war, daß auch bei der Gründung des BDO ein Geistlicher auftrat, woran im Juni 1944 bei der Gründung des kirchlichen Arbeitskreises des NKFD angeknüpft werden konnte ${ }^{109}$. Im Herbst 1943 jedoch mußte die KPD akzeptieren, daß von sowjetischer Seite den Vorstellungen der Offiziere mehr Beachtung geschenkt wurde als den ihrigen.

Die latente Konkurrenz zwischen BDO und (kommunistischem) NKFD führte um die Jahreswende 1943/44 zum heftigen Streit der deutschen Exilkommunisten untereinander. Ausgelöst wurde er durch die Frage nach dem Verhältnis der Redaktionsmitarbeiter im Institut $99 \mathrm{zu}$ den Kriegsgefangenen im Nationalkomitee ${ }^{110}$. Durch das Eingreifen Dimitrovs wurde der Konflikt Mitte Januar beigelegt. Er stellte die sowjetische Haltung insofern klar, als er die deutschen Kommunisten daran erinnerte, daß die „politische Orientierung in der Arbeit nach Deutschland

107 FD Nr: $1 / 1943$ vom 19. 7. 1943.

108 FD 8,9/1943 vom 15. 9. 1943, S. 2.

109 Eschborn und Klein beim NKFD, Kayser beim BDO.

110 Notizen Piecks vom 29. 12. 1943 und 2. 1. 1944, SAPMO-BArch NY 4036/498, Bl. 127-131 und ebenda Akte 499, Bl. 66-68; vgl. Müller-Enbergs, Der Fall Rudolf Herrnstadt, S. 43 ff. 
im Zusammenhang mit der Arbeit im Nationalkomitee" zu sehen sei ${ }^{111}$. Zugleich beauftragte Dimitrov die KPD mit der Ausarbeitung eines eigenen deutschlandpolitischen Konzepts.

Die KPD beschloß am 6. Februar 1944 die Einsetzung einer zwanzigköpfigen Kommission „zur Durcharbeitung einer Reihe politischer Probleme des Kampfes für den Sturz Hitlers und der Gestaltung des neuen Deutschlands"112. Aber erst Anfang März 1944, parallel zu dem alliierten Arbeitsstab der EAC, nahm diese Kommission ihre Arbeit auf113. Auf der Eröffnungssitzung stellte Florin die Grundposition der KPD klar: Bildung von Volksausschüssen zusammen mit bürgerlichen Kräften, aber unter Leitung der KPD. Dabei ging er auch auf die Zusammenarbeit mit dem BDO ein: „Der Kampf zur Brechung des faschistischen Terrors ist Sache des Volkes bzw. aller Volksschichten. Die Hauptkraft im Kampfe gegen diesen Terror werden die Arbeiter, Bauern und Soldaten sein. Aber wir [KPD] werden auch im Unterschied zu 1918 viele bürgerliche Menschen, ja, Generale haben, die diesen Terror mit brechen helfen (Seydlitz)." ${ }_{114}$ Einen Tag zuvor - am 5. März hatte sich Wilhelm Pieck mit den Generälen in Dombrovo getroffen und dort von deren Vorstellungen über die Bildung einer Exilregierung aus Offizieren und Emigranten erfahren. Angesichts der vollkommen unterschiedlichen Planungen von $\mathrm{BDO}$ und KPD, die beide mit sowjetischer Duldung betrieben, ergab sich nun ein direktes Konkurrenzverhältnis. Allerdings ist es fraglich, inwiefern durch das Seydlitz-Memorandum zwischen KPD und BDO „die Machtfrage“ gestellt wurde ${ }^{115}$, denn auch wenn die Positionen inhaltlich nicht weiter auseinanderliegen konnten, so war der KPD doch die sowjetische Haltung zum BDO/NKFD bekannt. Dimitrov hatte schließlich nochmals ausdrücklich darauf hingewiesen. Die Kommunisten im Nationalkomitee zeigten sich denn auch gegenüber den Vorschlägen des BDO zur Umstrukturierung des Nationalkomitees kompromißbereit. Nachdem sich der zivile Teil am 20. März im Institut 99 getroffen hatte, wurde Manuil'skij eine Entschließung übermittelt, die zu einer nahezu kompletten Übersiedlung des Stadtkomitees in das Lager Lunevo geführt hätte ${ }^{116}$. Jedoch wurde dieser Plan nicht realisiert. Statt dessen wurde das NKFD umstrukturiert und die Kontrolle durch das Institut 99 verbessert.

Erst nachdem die Pläne des BDO gescheitert waren, wurde die Arbeit des Nationalkomitees stärker von den im Institut 99 arbeitenden Kommunisten beeinflußt. Nun spielte die Programmkommission der KPD insofern eine Rolle, als ihre Ergebnisse direkt in die propagandistische Arbeit des Nationalkomitees einflossen. Wie schon im Sommer 1943 bei Gründung des Nationalkomitees war der Leitgedanke die Initiierung einer Volkserhebung zum Kampf aller Schichten gegen Hitler als

111 Notizen Piecks von einer Besprechung bei Dimitrov am 13. 1. 1944, SAPMO-BArch NY 4036/545, Bl. 27.

112 Protokoll der Leitungssitzung vom 6. 2. 1944, SAPMO-BArch NY 4036/499, Bl. 83.

113 Fischer, Sowjetische Deutschlandpolitik, S. 84f.; „Nach Hitler kommen wir“, S. $77 \mathrm{ff}$.

114 „Die Lage und die Aufgaben in Deutschland bis zum Sturz Hitlers“, handschriftliche Ausarbeitung Wilhelm Florins für das Referat vor der Arbeitskommission auf der Sitzung am 6. März 1944, in: „Nach Hitler kommen wir“, S. 153.

115 Heider, Nationalkomitee „Freies Deutschland“, S. 21.

116 Notizen Piecks von einer Besprechung am 20. 3. 1944, SAPMO-BArch NY 4036/575, Bl. 145; Weinert an Manuil'skij am 24. 3. 1944, RGASPI 495/77/38, Bl. 12. 
„Bewegung Freies Deutschland“. Allerdings sollte nach Vorstellung der Kommunisten nicht das Nationalkomitee in Moskau, sondern die von der KPD inspirierten Volksausschüsse in Deutschland die Führung der Bewegung übernehmen. Wilhelm Florin referierte darüber Anfang Juni 1944 in der KPD-Arbeitskommission: „Wir wählten als die demokratischen Organe der Volkserhebung Volksausschüsse in Stadt und Land, in denen Vertreter aller Volksschichten sein sollen. Diese Volksausschüsse sollen sich auf Kameradschaften oder Wehrmachtsgruppen in der Wehrmacht stützen. Sie sollen sich stützen auf Betriebskampfausschüsse - sie sollen sich stützen auf Vertrauensleute - sie sollen sich stützen auf alle illegalen Parteigruppen und Organisationen, die am Kampfe teilnehmen. Die Volksausschüsse sind demnach keine Organe einer Partei, sondern Organe der großen Bewegung ,Freies Deutschland' bzw. der nationalen Friedensbewegung. Die Führung in diesem nationalen Kampf haben also die Volksausschüsse."117 Auch wenn Florin in seine Ausführungen einflocht, „daß das, was ich hier sage, nicht alles in der Zeitung ,Freies Deutschland" gesagt werden kann" 118 , so konnten die Leitgedanken dennoch übernommen werden. Der erstmalige Aufruf des NKFD zur Bildung von Volksausschüssen erschien anläßlich der alliierten Landung in der Normandie am 11. Juni $1944 \mathrm{im}$ „Freien Deutschland“. Er richtete sich direkt an die deutsche Bevölkerung: „Schafft in allen Städten und Landgebieten Volksausschüsse zur Führung des nationalen Kampfes unseres Volkes. Die besten und mutigsten Männer unserer Heimat, die Vertreter der verschiedensten Schichten unseres Volkes und der verschiedenen politischen Anschauungen gehören in die Volksausschüsse. Die Zeit ist gekommen, wo im Rüstungsbetrieb wie in der Truppe, in Stadt und Land, in der Heimat und an der Front alle wahrhaft nationalbewußten Männer und Frauen unseres Volkes die Vorbereitung treffen zur Erhebung des Volkes gegen den Feind der Nation - gegen Hitler." 119

Die Einflüsse der KPD-Konzeption waren auch nicht zu übersehen, als auf der 10. Vollsitzung des NKFD (14. bis 17. Juni 1944) der „Kirchliche Arbeitskreis“ aus der Taufe gehoben wurde ${ }^{120}$. Auf dem NKFD-Plenum hielten mehrere NKFDund BDO-Mitglieder Referate, die alle unter dem Motto „Volk und Kirche gegen Hitler" standen. Geistliche waren von Anfang an in die Arbeit des Nationalkomitees eingebunden worden, und somit fiel es leicht, die Gründung des Kirchlichen Arbeitskreises als eine Initiative der im NKFD aktiven Theologen darzustellen. Ähnlich wie bei der Gründung des Nationalkomitees im Juli 1943 traten die Vortragenden als Vertreter der unterschiedlichsten Volksschichten auf (z.B. „Reichstagsabgeordneter Florin“, „Wirtschaftsprüfer Fleischer", „Kriegspfarrer Arndt", „Kaufmännischer Angestellter Zippel“) und propagierten die Bildung von Volksausschüssen als notwendige Form des Widerstandes gegen Hitler ${ }^{121}$. Im Anschluß an die Vollsitzung wurde in den Lagern für die Unterstützung des Kirchlichen Ar-

117 Ausarbeitung Wilhelm Florins „Über die Volkserhebung und die Bildung von Volksausschüssen“, die in der ersten Junihälfte 1944 entstand, in: „Nach Hitler kommen wir“, S. 194.

118 Ebenda, S. 197.

119 FD Nr. 24/1944 vom 11. 6. 1944, S. 1, in: Flugblätter des Nationalkomitees, S. 318.

120 Ihme-Tuchel, Arbeitskreis für kirchliche Fragen, S. 66.

121 FD Nr. 26/1944 vom 25. 6. 1944, S. 3, in: Flugblätter des Nationalkomitees, S. 322; siehe auch Christen im Nationalkomitee. 
beitskreises geworben, der ein Vorbild für entsprechend gebildete Volksausschüsse in Deutschland sei ${ }^{122}$.

Im Sommer 1944 kehrte das Nationalkomitee zu Organisationsformen zurück, die ganz zu Beginn seiner Tätigkeit - noch vor der Gründung des BDO - das öffentliche Auftreten bestimmt hatten. Dabei wurde der ursprüngliche Ansatz wiederbelebt, durch Kommissionen des Nationalkomitees Antworten zu allen gesellschaftlich relevanten Fragen im Nachkriegsdeutschland zu erarbeiten. Wie Weinert in seinem „Bericht über die Tätigkeit des Nationalkomitees“ mitteilte, seien bei der Komiteegründung die „Fachgruppen“ Wirtschaft, Sozialpolitik, Recht und Kultur eingesetzt worden, um Material für die Propaganda, Schulung und allgemeine Aufklärungsarbeit des NKFD zu erstellten ${ }^{123}$. Diese Kommissionen kamen aber, bedingt durch die Dominanz des Offiziersbundes bis März 1944, nicht zustande. Sie wurden erst im Frühjahr 1944 durch den Vorschlag General Lattmanns in der Form eines „Schattenkabinetts“ einer Exilregierung wieder aktuell. Doch inzwischen hatte die KPD eigene Arbeitsgruppen eingesetzt, so daß es von ihrer Seite keinen unmittelbaren Bedarf mehr gab. Vergleicht man die bei der Gründung des NKFD in den Referaten angeschnittenen Themen mit denen, die ab Februar 1944 in der Planungskommission der KPD bearbeitet wurden, so ergeben sich Überschneidungen in den Bereichen Wirtschaft, Bildung und Agrarpolitik ${ }^{124}$. Allerdings werden auch die Unterschiede deutlich. Das NKFD als klassenübergreifendes Volkskomitee behandelte nicht die Fragen partikularer Interessenvertretungen wie Gewerkschaften und Parteien. Die KPD als atheistische Partei dagegen setzte keine Referenten für Kirchenfragen ein. Die Initiierung des Arbeitskreises für kirchliche Fragen innerhalb des Nationalkomitees konnte somit die Arbeitskommission der KPD ergänzen und zugleich diejenigen "gesellschaftlichen Kräfte" einbinden, die in der KPD keinen Platz hatten. Das wiederum war der Grundgedanke eines Volksausschusses unter der führenden Rolle der KPD.

Das NKFD ging dazu über, seine Frontbevollmächtigten zur Schaffung von Volksausschüssen auf deutschem Boden anzuhalten. Die entsprechenden Beschlüsse fielen auf der 11. Vollsitzung vom 14. Juli 1944125. Wenige Tage später, am 19. Juli, wandte sich der Frontbevollmächtigte Willms deswegen an Erich Weinert. Ganz im Einklang mit den Beschlüssen des NKFD ging er davon aus, nach der Besetzung die Bildung von Volksausschüssen zu initiieren, und damit - obwohl im unklaren über die sowjetische Haltung zu Einzelfragen („Wie behandeln wir die Grenzfrage?") - besatzungspolitische Aufgaben zu übernehmen: „Wenn das NKFD in Ostpreußen oder in anderen von der RA [Roten Armee] besetzten Reichsgebieten zum mindesten eine Betreuung der Zivilbevölkerung übernimmt, so wird das die Existenzfrage des Komitees überhaupt sichern. "126 Willms' Brief, der die Zensur des GlavPURKKA passieren mußte, ließ die Politische Hauptverwaltung aktiv werden. Ihre Haltung war eindeutig. Umgehend instruierte Burcev, Chef

122 Ihme-Tuchel, Arbeitskreis für kirchliche Fragen, S. 68.

123 Weinert, Nationalkomitee, S. $30 \mathrm{f}$.

124 Wirtschaft (Ackermann), ideologische Umerziehung (Weinert), Bauern- und Agrarfragen (Hoernle), Protokoll der KPD-Sitzung vom 6. 2. 1944, in: „Nach Hitler kommen wir“, S. 132.

125 FD Nr. 30/1944 vom 23. 7. 1944, S. 4; Weinert, Nationalkomitee, S. 94.

126 Willms an Weinert am 19. 7. 1944, RGASPI 495/77/38, Bl. 41. 
der 7. Verwaltung, seinen Stellvertreter Braginskij, der die 7. Verwaltung im Institut 99 vertrat, daß Frontbevollmächtigte des NKFD keinerlei Arbeit unter der Zivilbevölkerung aufnehmen dürften. Ihre Tätigkeit habe sich ausschließlich auf die Propaganda unter den Wehrmachtssoldaten zu beschränken 127.

Das zukünftige Auftreten des NKFD in dem von der Roten Armee besetzten Gebiet des Deutschen Reiches wurde auch im Institut 99 diskutiert. Während im Frontbereich per Anweisung des GlavPURKKA sofort klare Verhältnisse geschaffen wurden, mußten die Mitarbeiter des Instituts 99 in einem langwierigen Prozeß ihr weiteres Vorgehen mit der sowjetischen Führung abstimmen. Ernö Gerö, der Zensor der 7. Verwaltung im Institut 99, leitete die Nachfrage von Willms an Dimitrov weiter, um eine grundsätzliche Klärung durch die politischen Entscheidungsträger herbeizuführen: „Die Frage darüber, wie die Tätigkeit des Nationalkomitees ,Freies Deutschland' auf deutschem Territorium aussehen wird, wenn die Rote Armee dorthin vorgerückt sein wird, und ob überhaupt eine öffentliche Tätigkeit des Nationalkomitees entfaltet wird, gewinnt nun eine äußerst aktuelle Bedeutung. (...) Ich bitte Sie, sofern es möglich ist, sich dafür einzusetzen, daß wir in der genannten Angelegenheit eine Direktive erhalten. "128 Die sowjetische Position war unklar. Bereits am 17. Juli 1944 hatte der Zivilsektor im Institut 99 auf seiner Sitzung den ersten Entwurf eines Aufrufes beraten, mit dem sich das NKFD aus Anlaß des Überschreitens der deutschen Reichsgrenze zu Wort melden würde. $\mathrm{Zu}$ der von Willms angeschnittenen Frage der Grenzen („Ostpreußenfrage“) konnten die Mitarbeiter des Instituts 99 lediglich konstatieren, „keine endgültige und bindende Antwort zu geben, da Entscheidungen noch nicht getroffen werden können "129. Die weiteren Diskussionsprozesse lassen sich mangels Quellen im einzelnen nicht nachvollziehen und nur am Ergebnis, d. h. an der Propaganda, festmachen. Der vom NKFD schließlich veröffentlichte Aufruf erschien nach fünfwöchiger Bearbeitungszeit und enger Abstimmung mit Dimitrov am 27. August im „Freien Deutschland“130. Nun rief das Nationalkomitee nicht mehr zur Bildung von Volksausschüssen auf. Statt dessen wurde das aktive Handeln der „Roten Armee und ihrer Verbündeten“, aber mit keinem Wort das des Nationalkomitees herausgestellt. Das deutsche Volk wurde aufgefordert, zu retten was zu retten sei, wobei es über die Absichten der Befreier mit knappen Worten hieß: „Die Rote Armee und ihre Verbündeten haben kein anderes Ziel, als die Hitlerherrschaft zu vernichten, um ihre Länder für alle Zeit gegen die Überfälle solcher Räuber zu sichern."131 Über eine allgemeine Willensbekundung zum Sturz Hitlers ging dieser Aufruf nicht hinaus. Vertreter des Nationalkomitees übernahmen keinerlei Aufgaben, die mit der sowjetischen Besatzungspolitik in Berührung hätten kommen können. Vor allem legte der Appell die Sowjetunion politisch nicht fest.

Das sowjetische Zögern im Sommer 1944, sich auf eine klar formulierte Deutsch-

127 Vsevolodov, Vzaimodejstvie politorganov, S. 125.

128 Gerö an Dimitrov am 4. 8. 1944, RGASPI 495/77/38, Bl. 40.

129 Beschlußprotokoll des Instituts 99 vom 17. 7. 1944, RGASPI 495/77/46, Bl. 6.

130 Erster Beschluß im Institut 99 am 17. 7. 1944 (RGASPI 495/77/46, Bl. 6), erneuter Beschluß am 7.8. 1944 (ebenda, Bl. 9), Rücksprache Gerös bei Dimitrov am 11.8. 1944 (ebenda 495/77/38, Bl. 42-47).

131 „Alle Waffen gegen Hitler! Deutsches Volk, Männer und Frauen!“, FD 35/1944 vom 27. 8. 1944, S. 1; als textidentisches Flugblatt in: Flugblätter des Nationalkomitees, S. 248 f. 
landpolitik festzulegen, wurde durch den plötzlich eintretenden propagandistischen Erfolg des Nationalkomitees überdeckt. Generalleutnant Vincenz Müller, der Teile der bei Minsk eingekesselten 4. Armee der Heeresgruppe Mitte kommandierte, befahl eigenmächtig am 8. Juli, den Kampf einzustellen. Selbst wenn Müller den Befehl zur Kapitulation offensichtlich erst gab, nachdem er selbst in Gefangenschaft geraten war, wurde seine Erklärung sofort im „Freien Deutschland“ als „historische Tat" gerühmt ${ }^{132}$. In der nächsten Ausgabe folgte ein Aufruf von 17 Generälen, die angesichts des militärischen Zusammenbruchs der Ostfront unter der Offensive der Roten Armee „zur festen Überzeugung von der Aussichtslosigkeit eines weiteren Kampfes" gekommen waren ${ }^{133}$. Schließlich kam es am 20. Juli mit dem Attentat auf Hitler zu der vom NKFD seit einem Jahr geforderten Auflehnung deutscher Offiziere. Das Komitee schien kurz vor dem Erreichen seiner Ziele zu sein. Der Attentatsversuch wurde zum „Motor der Generalspropaganda"134, die durch den Beitritt von Generalfeldmarschall Paulus einen zusätzlichen Schub bekam.

Anfang August schloß sich Paulus endlich dem Nationalkomitee an. Der Aufruf der 17 Generäle soll auf ihn einen solch starken Eindruck gemacht haben, daß er um eine Aussprache mit dem ihm persönlich bekannten General Müller gebeten habe ${ }^{135}$. Müller, der - zumindest laut sowjetischer Darstellung - eng mit der operativen Abteilung des UPVI kooperierte, stimmte den schwankenden Paulus soweit um, daß das UPVI einen erneuten Versuch unternahm, den Generalfeldmarschall für die Mitarbeit im NKFD zu gewinnen. In mehreren Gesprächen mit UPVI-Chef Petrov und dem Politoffizier Wolf Stern entstand dabei eine Situation, die an die Unterredungen Mel'nikovs mit den Generälen im August 1943 erinnerte. Petrov trat gegenüber Paulus als Vertreter der sowjetischen Regierung auf und offerierte ihm die "Mitwirkung in Organen der Selbstverwaltung auf dem befreiten Territorium Deutschlands"136. Darüber hinaus bedeutete Stern dem Generalfeldmarschall, $\mathrm{da}$ mit seinem „Beitritt zur Bewegung die Repräsentation eines neuen demokratischen Deutschland zu einem ernstzunehmenden Faktor [wird], den man nicht vernachlässigen kann, wenn das Schicksal des künftigen Deutschland entschieden wird“137. Paulus wurde isoliert im „Objekt Nr. 35“ untergebracht, wo er mit Duldung des UPVI begann, in Konkurrenz zur Führung des NKFD einen eigenen Mitarbeiterstab zusammenzustellen ${ }^{138}$. Diesen Vorbereitungen machte das Institut

132 FD Nr. 30/1944 vom 23. 7. 1944, S. 1 und 3; Flugblätter des Nationalkomitees, S. 332 f.; vgl. Scheurig, Verräter oder Patrioten, S. 156.

133 FD Nr. 31/1944 vom 30. 7. 1944, S. 3; Flugblätter des Nationalkomitees, S. 335. Als 17. General schloß sich Hoffmeister dem Aufruf an; siehe auch Diesener, Der Beitritt kriegsgefangener Generale, S. $455 \mathrm{ff}$.

134 Flugblätter des Nationalkomitees, S. 327.

135 Bericht der operativen Abteilung des UPVI vom 25. 7. 1944, in: Reschin, Feldmarschall im Kreuzverhör; S. 111.

136 Bericht der operativen Abteilung des UPVI (Stern) vom 2. 8. 1944, ebenda, S. 113.

137 Bericht der operativen Abteilung des UPVI (Stern) vom 4. 8. 1944, ebenda, S. 114. Tatsächlich unterbreitete Paulus Ende Oktober 1944 in einem an Stalin persönlich adressierten Brief den Vorschlag einer Befreiungsarmee, Paulus an Stalin am 30. 10. 1944, ebenda, S. 134. Der ganze Vorgang ist ebenfalls dokumentiert durch Reschin, Die Bemühungen um den Eintritt von Generalfeldmarschall Paulus in das NKFD, S. $239 \mathrm{ff}$.

138 Vgl. Berichte der operativen Abteilung des UPVI vom 9. 8.-13. 8. 1944, Reschin, Feldmarschall im Kreuzverhör, S. $123 \mathrm{ff}$. 
99 am 14. August ein Ende: „Ein im BDO erwogener Vorschlag, Generalfeldmarschall Paulus zum Ehrenpräsidenten des BDO wählen zu lassen, wird vorläufig zurückgestellt, bis die entsprechenden politischen Voraussetzungen bei Paulus geschaffen sein werden und er eine klare Stellung zur Armee einnimmt. Unter Umständen ist eine Neuwahl des Vorstandes des $\mathrm{BDO}$ zu erwägen, um einige inaktive Elemente durch geeignetere Personen zu ersetzen."139 Auch wenn durch diese schwammige Formulierung immer noch eine Alternative offenblieb, was für die „operative Arbeit" durchaus typisch war, so wurde Paulus aufgrund des Einspruchs aus dem Institut 99 keine politische Führungsrolle zugewiesen. Die Diskussion um das NKFD als Exilregierung war seit dem Frühjahr 1944 abgeschlossen. Sie wurde auch nicht durch den Beitritt Paulus zum NKFD wiederbelebt.

$\mathrm{Ab}$ August 1944 stützte sich die Propaganda des NKFD bevorzugt auf Generalfeldmarschall Paulus und die neu in den BDO eingetretenen Generäle. In der öffentlichen Begründung des Beitritts des Generalfeldmarschalls wurde die - ideelle Verbindung zu den Attentätern vom 20. Juli hergestellt ${ }^{140}$. Im Dezember 1944 schließlich unterschrieben 50 Generäle mit Paulus an der Spitze einen Aufruf, in dem sie den Krieg für verloren erklärten, eine Auflehnung gegen Hitler und einen sofortigen Friedensschluß forderten. Dieser Appell wurde von über drei Viertel aller in sowjetischer Gefangenschaft befindlichen Wehrmachtgeneräle unterschrieben und war damit zweifellos der größte Erfolg des NKFD/BDO in den Offizierslagern ${ }^{141}$. Er wurde im „Freien Deutschland“ und in der sowjetischen Presse groß aufgemacht ${ }^{142}$.

Während sich die Arbeit im Institut 99 in der zweiten Jahreshälfte 1944 stark auf die "Generals-Propaganda" konzentrierte, kam die Programmdiskussion der KPD zu einem Ende. Im Oktober 1944 begannen die Emigranten, die Ergebnisse der Arbeitskommission zusammenzuschreiben. Insgesamt gab es wegen der von Dimitrov immer wieder vorgenommenen Korrekturen vier verschiedene Versionen des „Aktionsprogrammes des Blockes der kämpferischen Demokratie“. Erst Ende November 1944 lag die endgültige, den sowjetischen Vorstellungen entsprechende Schlußfassung vor ${ }^{143}$. So war es kein Zufall, daß es Ende November/Anfang Dezember $1944 \mathrm{zu}$ einem Gespräch zwischen den führenden kommunistischen und kriegsgefangenen Mitgliedern des Nationalkomitees, den verantwortlichen Mitarbeitern von 7. Verwaltung des GlavPURKKA (Braginskij) und UPVI (Švec) sowie des Instituts 99 (Kozlov) kam. Der genaue Ablauf der insgesamt zwei Zusammenkünfte ist aufgrund der schlechten Quellenlage nicht genau zu rekonstruieren, sie stellen aber den Wendepunkt in der sowjetischen Haltung zum NKFD dar.

Die Aussprache drehte sich - den Notizen Piecks zufolge - abermals um die

139 Beschlußprotokoll des Instituts 99 vom 14. 8. 1944, RGASPI 495/77/46, Bl. 12.

140 FD Nr. 34/1944 vom 20. 8. 1944, S. 1; Flugblätter des Nationalkomitees, S. 342; vgl. Dreetz, Der Weg und Bekenntnis des Generalfeldmarschalls Friedrich Paulus, S. 99 f.; siehe auch Görlitz, Ich stehe hier auf Befehl; Finker, Die Stellung der Sowjetunion und der sowjetischen Geschichtsschreibung zum 20. Juli, S. $47 \mathrm{ff}$.

141 Ein Bericht des UPVI an Stalin und Molotov vom 5. 12.1944 meldete 74 kriegsgefangene Generäle (nicht nur deutsche), RGVA/K 1p/9a/8, Bl. 148.

142 FD Nr. 50/1944 vom 10. 12. 1944, S. 1; Flugblätter des Nationalkomitees, S. 399 ff.; Aufruf "An Volk und Wehrmacht" vom 8. 12.1944, in: Das Nationalkomitee „Freies Deutschland“ und der Bund Deutscher Offiziere, S. $283 \mathrm{ff}$.

143 Siehe "Nach Hitler kommen wir", S. $93 \mathrm{ff}$. 
Frage, um die bereits im Frühjahr 1944 gestritten worden war: „Rolle des Nationalkomitees, Perspektive ob Regierung". Hinzu kamen Fragen nach der sowjetischen Deutschlandpolitik („Grenzfrage, Entwaffnung“, „Frage der Demokratie, wieviel Parteien“), dem Programm der KPD („Block der kämpferischen Demokratie“) und der Zukunft der Wehrmacht („Befreiungsarmee/Schutztruppe“, „Frage der Zukunft der Berufsoffiziere")144. Am 22. November 1944 legte Braginskij in einem Grundsatzreferat den Standpunkt des GlavPURKKA dar. Anschließend äußerte sich Pieck über das „Vertrauensverhältnis zwischen den Kommunisten und den übrigen Mitgliedern im Nationalkomitee“, das er als mangelhaft darstellte: Die Bewegung „Freies Deutschland“ habe zwar den richtigen Weg aufgezeigt, sei daher auch ein gutes Beispiel für das Zusammengehen antifaschistischer Kräfte im neuen Deutschland, doch leider sei man über diese Anfänge nicht hinausgekommen, weil insbesondere „das für unsere Zusammenarbeit notwendige unbegrenzte Vertrauen zu uns Kommunisten im Nationalkomitee" gefehlt habe ${ }^{145}$. In der zweiten Zusammenkunft folgte am 5. Dezember die Aussprache über die Referate, an deren Ende Braginskij ein zusammenfassendes Schlußwort sprach. Offenbar war von Seiten des $\mathrm{BDO}$ eine verbindliche Erklärung über die sowjetischen Absichten in Deutschland gefordert worden, denn Braginskij ging auf diese Frage ein. Er tat sie jedoch mit allgemeinen Hinweisen auf die Ausführungen Stalins in der Vergangenheit ab: „Das Besatzungsregime der Sowjetunion ist im Wesen der Sowjetunion selbst zu suchen. Die zeitweiligen Maßnahmen können schwer sein, aber doch sind sie ausgerichtet auf die Freundschaft der Völker. Die beste Deklaration besteht im Vertrauen auf die Worte und die Bücher Stalins, wofür bereits über 25 Jahre Sowjetentwicklung vorliegen." 146 Gleichzeitig machte Braginskij klar, daß der weitere Weg in der sowjetischen Deutschlandpolitik in enger Zusammenarbeit mit der KPD erfolgen werde. An den BDO gewandt und unter direktem Hinweis auf den Aufruf der 50 Generäle betonte er, daß „die deutschen Patrioten“ immer noch ihre Autorität dafür einsetzen könnten, um in der Schlußphase des Krieges die Opfer auf beiden Seiten möglichst gering zu halten. Weitergehende Aufgaben sprach er ihnen jedoch nicht $\mathrm{zu}^{147}$.

Das Ergebnis der Aussprache war für den BDO unbefriedigend. Eine verbindliche Erklärung über die sowjetischen Ziele und die Zukunft des Nationalkomitees wurde nicht gegeben und gleichzeitig das sowjetische Zusammengehen mit der KPD demonstrativ zur Schau gestellt. Die Zusammenkunft war das letzte Spitzengespräch zwischen BDO, GlavPURKKA und UPVI. Seydlitz berichtet, daß sich die sowjetischen Vertreter seit Dezember 1944 in offener Form von ihm zurückzogen und der BDO vom Kriegsende schließlich nur noch aus der Zeitung erfahren habe ${ }^{148}$. So bitter Seydlitz die Ablsehr der sowjetischen Führung vom

144 Ebenda, S. 310.

145 Rededisposition Piecks, ebenda, S. 304 ff. Pieck nimmt eingangs Bezug auf seinen Vorredner Braginskij, über dessen Referat keine Aufzeichnungen vorliegen.

146 „Auszüge aus dem Schlußwort des Genossen Braginskli (5. 12. 1944)“, SAPMO-BArch NY 4036/575, Bl. 225-226; vgl. Notizen Piecks über die "Zusammenkunft am 5.12. 1944", SAPMO-BArch NY 4036/575, Bl. 218-223.

147 „Auszüge aus dem Schlußwort des Genossen Braginski (5. 12. 1944)“, SAPMO-BArch NY 4036/575, Bl. 227.

148 Seydlitz, Stalingrad, S. 355; vgl. Seydlitz' Aussagen während einer Befragung durch das 
BDO auch erschienen sein mag, so heißt das aber im Umkehrschluß auch, daß ungeachtet des Eklats um das Seydlitz-Memorandum die sowjetische Führung bis Dezember 1944 dem NKFD eine gewisse politische Funktion zugeschrieben hatte. Zwar hatte die Politische Hauptverwaltung bereits im Juli 1944, noch bevor die Rote Armee deutschen Boden betrat, deutlich gemacht, daß sich die unmittelbare Besatzungsverwaltung nicht auf das Nationalkomitee bzw. seine Frontbevollmächtigten stützen würde, aber eine politische Entscheidung darüber wurde bis zum Jahresende 1944 hinausgezögert. Endgültig fiel sie erst im Zuge der alliierten Konferenz von Jalta Anfang Februar 1945. Erst danach ordnete das OMI an, die Zeitung „Freies Deutschland“ in Auflage und Umfang einzuschränken und sie nur noch in den Kriegsgefangenenlagern oder im unmittelbaren Frontbereich zu verbreiten, d.h. nicht in dem bereits von der Roten Armee besetzten Gebiet. Pieck, der die KPD-Spitze am 19. Februar über Dimitrovs Anweisungen informierte, stellte klar, daß die Tätigkeit des Nationalkomitees zu beenden sei. Das Schwergewicht der kommenden Arbeit läge auf der Unterstützung der sowjetischen Besatzungspolitik, die nicht im Namen des NKFD erfolge ${ }^{149}$. Damit hatte das Nationalkomitee seine deutschlandpolitische Funktion verloren.

Militärgeschichtliche Forschungsamt am 13. 3. 1969: „... also Ende 44, Anfang 45. Da hörte eigentlich die ganze Tätigkeit des BDO fast restlos auf. Da haben wir eigentlich nichts mehr gemacht. Der BDO blieb noch bestehen bis zum Hubertus [3. November] 45, aber ohne irgendeine Tätigkeit.", BArch-MA N 55/22, Bl. 31.

149 „In Moskau, Zeitung Freies Deutschland in Auflage u. Umfang einschränken; nur für Kriegsgefangene u. für Hitlerfront. Tätigkeit des Nat.Kom. langsam eingeschränkt Schwergewicht der Arbeit verlegen auf deutsches Gebiet - (...)“, Notizen Piecks über eine „Besprechung [der KPD] am 19.2.1945“, in: "Gruppe Ulbricht“, S. 232; vgl. Notizen Piecks über die „Besprechung bei Dimitroff am 19.2. 1945“, ebenda, S. $227 \mathrm{ff}$. 